Article

\title{
Earth Observation and Biodiversity Big Data for Forest Habitat Types Classification and Mapping
}

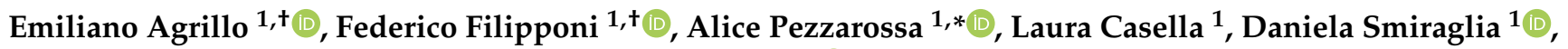 \\ Arianna Orasi ${ }^{1}$, Fabio Attorre ${ }^{2}$ and Andrea Taramelli ${ }^{1,3}{ }^{\mathbb{D}}$ \\ 1 Italian National Institute for Environmental Protection and Research (ISPRA), Via Vitaliano Brancati 48, \\ 00144 Roma, Italy; emiliano.agrillo@isprambiente.it (E.A.); federico.filipponi@isprambiente.it (F.F.); \\ laura.casella@isprambiente.it (L.C.); daniela.smiraglia@isprambiente.it (D.S.); \\ arianna.orasi@isprambiente.it (A.O.); andrea.taramelli@isprambiente.it (A.T.) \\ 2 Department of Environmental Biology, University of Roma "La Sapienza", Piazzale Aldo Moro 5, \\ 00185 Roma, Italy; fabio.attorre@uniroma1.it \\ 3 IUSS-Istituto Universitario di Studi Superiori di Pavia, Palazzo del Broletto-Piazza della Vittoria 15, \\ 27100 Pavia, Italy \\ * Correspondence: alice.pezzarossa@isprambiente.it; Tel.: +39-06-5007-2218 \\ + These authors contributed equally to this work.
}

Citation: Agrillo, E.; Filipponi, F.; Pezzarossa, A.; Casella, L.; Smiraglia, D.; Orasi, A.; Attorre, F.; Taramelli, A. Earth Observation and Biodiversity Big Data for Forest Habitat Types Classification and Mapping. Remote Sens. 2021, 13, 1231. https:// doi.org/10.3390/rs13071231

Academic Editor: Nicholas Coops

Received: 26 January 2021

Accepted: 22 March 2021

Published: 24 March 2021

Publisher's Note: MDPI stays neutral with regard to jurisdictional claims in published maps and institutional affiliations.

Copyright: (C) 2021 by the authors. Licensee MDPI, Basel, Switzerland. This article is an open access article distributed under the terms and conditions of the Creative Commons Attribution (CC BY) license (https:// creativecommons.org/licenses/by/ $4.0 /)$.

\begin{abstract}
In the light of the "Biological Diversity" concept, habitats are cardinal pieces for biodiversity quantitative estimation at a local and global scale. In Europe EUNIS (European Nature Information System) is a system tool for habitat identification and assessment. Earth Observation (EO) data, which are acquired by satellite sensors, offer new opportunities for environmental sciences and they are revolutionizing the methodologies applied. These are providing unprecedented insights for habitat monitoring and for evaluating the Sustainable Development Goals (SDGs) indicators. This paper shows the results of a novel approach for a spatially explicit habitat mapping in Italy at a national scale, using a supervised machine learning model (SMLM), through the combination of vegetation plot database (as response variable), and both spectral and environmental predictors. The procedure integrates forest habitat data in Italy from the European Vegetation Archive (EVA), with Sentinel-2 imagery processing (vegetation indices time series, spectral indices, and single bands spectral signals) and environmental data variables (i.e., climatic and topographic), to parameterize a Random Forests (RF) classifier. The obtained results classify 24 forest habitats according to the EUNIS III level: 12 broadleaved deciduous (T1), 4 broadleaved evergreen (T2) and eight needleleaved forest habitats (T3), and achieved an overall accuracy of 87\% at the EUNIS II level classes (T1, T2, T3), and an overall accuracy of $76.14 \%$ at the EUNIS III level. The highest overall accuracy value was obtained for the broadleaved evergreen forest equal to $91 \%$, followed by $76 \%$ and $68 \%$ for needleleaved and broadleaved deciduous habitat forests, respectively. The results of the proposed methodology open the way to increase the EUNIS habitat categories to be mapped together with their geographical extent, and to test different semi-supervised machine learning algorithms and ensemble modelling methods.
\end{abstract}

Keywords: forest habitat; habitat classification; habitat mapping; habitat monitoring; Random Forests; supervised machine learning modelling; Sentinel-2; Copernicus

\section{Introduction}

Global-scale environmental issues, from climate change to biosphere integrity [1], are creating an intense social pressure and a growing need for information with appropriate reliability and suitable spatial scale (from the local to global analysis and vice versa) that must be provided by the scientific community [2-5].

Therefore, it is strictly urgent to ensure the integrity of the Bio, Hydro, and Geosphere by following the advance of the high technologies. The High-Tech frontier looks further 
ahead than the growing results obtained from environmental sciences research, which, in certain fields, still trudges due to the inaccessibility of large datasets [6].

It is reasonable that the potential availability of a huge amount of "big data" in the future will allow for the use of advanced analytic techniques, extracting useful information from different large datasets, including those observing and measuring the ecosystem processes in response to environmental drivers of changes [7]. A multidisciplinary approach, including machine learning techniques, data mining, big data analytics, and ecological modelling, is highly recommended to interpret ecological processes and identify adequate solutions for the Anthropocene environmental issues [8]. However, the use of big data today represents a big challenge, from detailed analysis on specific topics or geographic areas to issues at wider scales and over broader timescales [5].

In light of the "Biological Diversity" concept $[9,10]$, habitats are cardinal pieces for biodiversity quantitative estimation at the local and global scale. They are basic units of ecosystems and biomes, which are identified by abiotic environmental factors, such as climate, geomorphology, pedology, as well as by plant species composition (i.e., vegetation units) [11-13]. The main criterion that assesses spatial symptoms of habitat collapse is the reduction of the area of occupancy over time, according to the European Red List of Habitats [14]. Indeed, records of occurrence and abundance of plant species, which represent the origin of data for the habitat identification, are an irreplaceable source of information needed to evaluate and monitor the favourable/unfavourable conservation status of the habitats [15]. Starting from 2010, efforts in establishing vegetation databases at a continental scale e.g., [16-18], led to the renewing of the EUNIS (European Nature Information System) classification, the comprehensive hierarchical pan-European system for habitat identification [19-21], with clearly defined units that are useful for their assessments and with a coherent ecological and biogeographical background [22].

The EUNIS habitat classification is developed and maintained by the European Environmental Agency, for policy-related ecosystem and habitat assessments [23]. It constitutes the mandatory reference lists for national and regional classifications for geospatial mainstream data sharing.

Moreover, Earth Observation (EO) data that are acquired by satellite sensors offer new opportunities for environmental sciences and are revolutionizing the methodologies applied, from experimental/theoretical to computational science [24], projecting big data from space in the mainstream of the ecological analysis. Therefore, it is easily foreseeable that, in the next decades, new technologies that are based on EO data will affect ecosystem surveys, mapping, and monitoring, thus opening a new era [25]. Recently, several scientific projects and studies have focused on natural habitats detection and the monitoring of their conservation status by using EO products [26-31]. Satellite data have been used for mapping grasslands using multitemporal high resolution optical and multispectral optical data [32], forest communities using NDVI time series [33], coastal habitats using spectral mixing analysis [34,35], phenological analysis using Sentinel-2 vegetation indices time series [36,37], or the assessment of plant functional types using radar backscatter [38].

The requirements of global, continental, and national policies on environment sustainability give a new impulse in this direction [39,40], as stated in the European Biodiversity Strategy 2030, a core part of the European Green Deal, and in the 2030 Agenda for Sustainable Development $[41,42]$. The increasing demand from national institutions for updated information to monitor ecosystems and detect their changes in time and space plays a crucial role in demonstrating spatial products as an essential tool for biodiversity assessments $[28,43]$. In this direction, the EU Copernicus Programme, especially through the Copernicus Land Monitoring Service (CLMS) [44] and the launch of Sentinel Earth observation satellite constellations, provides information services and it is promoting and supporting common frameworks for an updated land environmental monitoring at a European (local and in situ) [45,46] and global scale [47].

In the last decades, the habitat distribution modelling (HDM) has been used to predict the distribution of habitats across landscapes using their relationship with the environ- 
mental variables, similarly to the species distribution models [48-50]. Although HDM often uses environmental big data, such as climate or geomorphology variables, to detect the habitat distribution, only recently has their combination with the EO data been applied [50-53]. Moreover, many research initiatives experimented with several multidisciplinary approaches, including: the use of ensemble modelling (i.e., Random forests) for mapping individual tree species at high spatial resolution [50], the hierarchical habitat classification models using very high resolution satellite optical multispectral data [54], and the evaluation of input features for tree species classification [55].

Along with supporting policies on environment sustainability using spatial products on biodiversity assessments, comes the need for procedures to generate habitat mapping products that could cover wide geographical areas with standard classification coding and legend, and reasonably undertake a multidisciplinary approach combining big data analytics, ecological modelling, and Earth Observation data, providing unprecedented insights for the monitoring of Sustainable Development Goals (SDGs) indicators [56].

This article shows a first result of a novel approach for a spatially explicit habitat mapping of forest in Italy using a supervised machine learning model and the combination of vegetation dataset, high resolution EO data, and environmental variables. The obtained results could be useful for monitoring the spatial patterns of ecosystems in space and time.

The specific objectives of this study are: (i) to present a procedure to generate habitat mapping products combining environmental, EO, and vegetation big data with high spatial and thematic resolution; (ii) to evaluate the importance of predictor variables deriving from different data source for the classification of forest habitat types; and, (iii) to demonstrate the effectiveness of the developed hierarchical classification scheme for the habitat identification in the Italian national territory.

\section{Materials and Methods}

In ecology, HDMs link data on the distribution of habitat to abiotic or biotic conditions [57] that are also derived from remote sensing data. Typically, the starting point of HDM is location data on the occurrence of a habitat as response variable, and mapped environmental or satellite data as predictors [58]. Statistical methods, such as Random Forests, are used to estimate the presence of habitat as a function of the predictor variables.

\subsection{Research Step Flowchart}

Describing the classification procedure of forest habitats used here was not effortless, so the flowchart that is presented in the Figure 1 summarizes and visualizes the single stages processed in the text. 


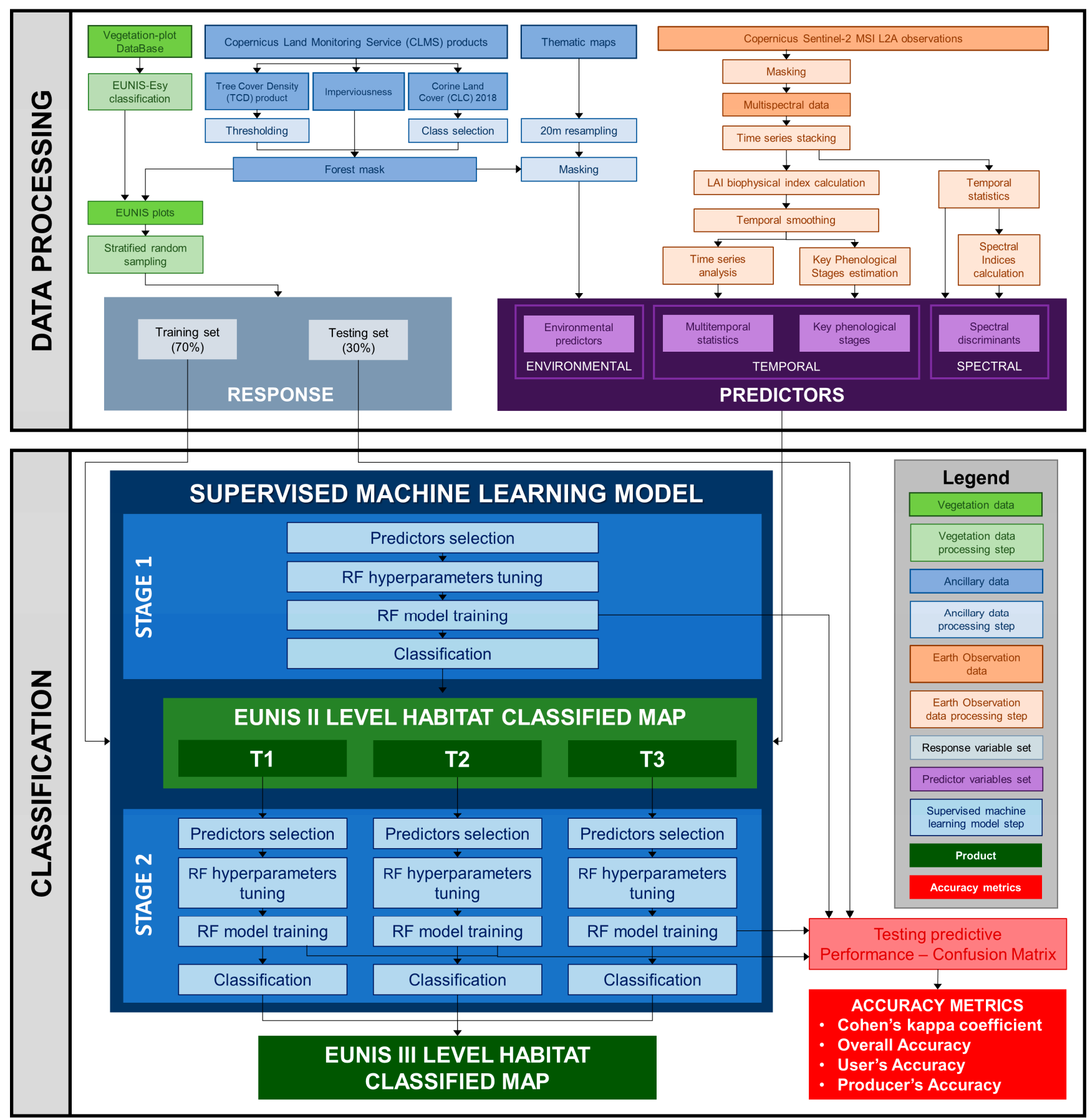

Figure 1. Flowchart of the approach for forest habitat mapping using a supervised machine learning model. For more details about EUNIS codes (i.e., II and/or III level) see Table 3.

\subsection{Study Area}

The study area encompasses Italy (Figure 2), which covers about $300.000 \mathrm{~km}^{2}$, and it is characterized by a noteworthy geo-morphological and land use heterogeneity (there are two mountain ridges, the Alps in the northern, and the Apennines in the southern), as a result of complex tectonics processes starting from the Upper Cretaceous and centuries-old land management, respectively [59]. The area also shows a marked climatic variability, from the Mediterranean climate along the central and southern coasts, up to the alpine in the mountains [60]. 
The land use is characterized by three main classes: croplands (51.46\%), natural $(43.05 \%)$, and urban areas $(5.49 \%)[44,61]$. Within the natural areas, the woodlands and forests cover $85830 \mathrm{~km}^{2}$, corresponding to the $28.5 \%$ of total land surface [62]. The forest habitat (shrublands and tree plantations excluded) was subdivided in nine forest types [63], as shown in Table 1.

Table 1. The forest types present in Italy according to the National Forest Inventory of $2005^{1}$ and the European Atlas of Forest Tree Species ${ }^{2}$.

FOREST TYPE DOMINANT SPECIES

Hemiboreal forest and nemoral coniferous and mixed broadleaved coniferous forest

Alpine coniferous forest

Coniferous forests of the Mediterranean, Anatolian and Macaronesian regions Mesophytic deciduous forest Mountainous beech forest

Thermophilus deciduous forest

Broadleaved evergreen forest Floodplain forest
Picea abies (Norway spruce), Pinus pinaster (Maritime pine), Pinus sylvestris (Scots pine) and Pinus nigra (Black pine) P. abies, Larix decidua (European larch), Pinus mugo (Bog pine), Pinus cembra (Swiss pine) and Abies alba (European silver fir) P. pinaster, Pinus halepensis (Aleppo pine), Pinus pinea (Stone pine), Pinus heldeeicrii (Bosnian pine) Carpinus betulus (Common hornbeam)

Fagus sylvatica (Europe beech) and A. alba (European silver fir) Deciduous Oaks, Tilia spp. (little leaf linden), Ostrya carpinifolia (European hop-hornbeam) and Castanea sativa (sweet chestnut) Quercus ilex (evergreen oak) and Quercus suber (cork oak) Salix spp (Willow), Populus spp. (Poplar) and Alnus glutinosa, (Common alder) Alnus cordata (Italian alder)

Not riverine alder, birch, or aspen forest

${ }^{1}$ https:/ / www.sian.it/inventarioforestale/ (accessed on 14 December 2020); ${ }^{2}$ https: / / forest.jrc.ec.europa.eu/en/ european-atlas/ (accessed on 23 October 2020).

Over centuries, along the Italian peninsula these climatic, morphological, and land use features have defined peculiar geographic regions with similar environmental conditions, which support plant and animal species with comparable life strategies and adaptations (i.e., the biogeographical regions) [64]. Indeed, in 2011 from EU Member States consultation meetings, following Article 17 of the Habitats Directive (92/43/EEC) and Natura 2000 Biogeographical processes, the biogeographical regions were defined for the whole Europe [65]. Italy is included in three Biogeographical regions (see Figure 2): Mediterranean (characterized by hot dry summers and humid, cool winters); Alpine (where extreme temperatures and annual precipitation are strictly related to the physiography and in late fall and winter all precipitation above $1500 \mathrm{~m}$ a.s.l. is in the form of snow); and, Continental (with significant annual variation in temperature, hot summers, and cold winters, and precipitation tends to be moderate, being mostly concentrated in the warmer months) [60]. 


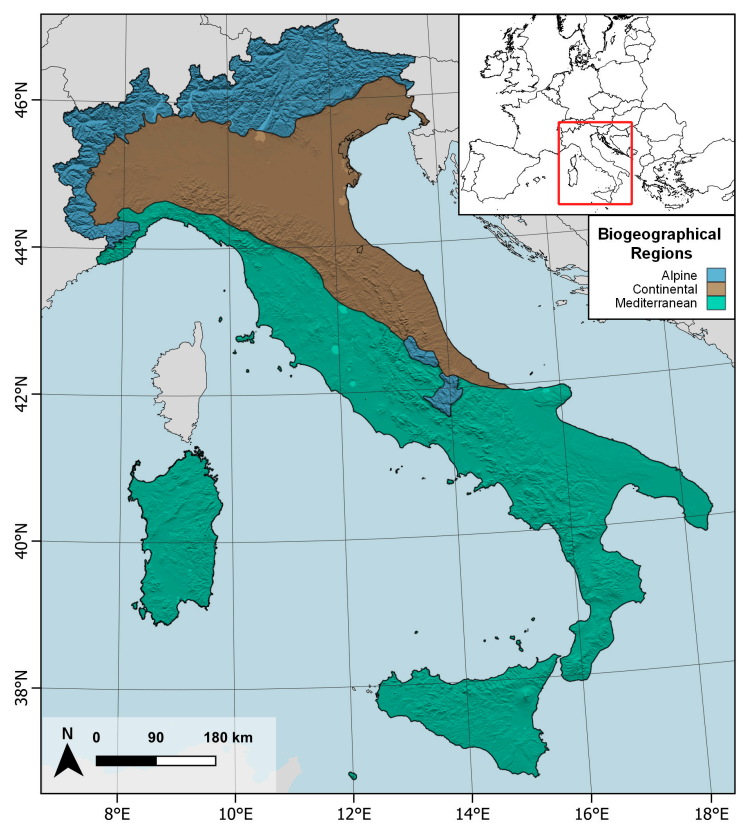

Figure 2. Overview of the Italian territory at continental scale and the distribution of European biogeographical regions (adapted from [65]).

\subsection{Data Gathering and Processing}

\subsubsection{Response Variable}

The primary source for producing the EUNIS forest habitat classification is a dataset extracted by the European Vegetation Archive $[17,66]$. The archive collects records of vegetation plots, which include: a full list of vascular plant species; the estimates of cover abundance for each species; georeferenced point location; and, additional information on vegetation structure and environmental plot features. Vegetation plots that are larger than $200 \mathrm{~m}^{2}$ and that only reported species composition without cover abundance information have been excluded.

The final forest vegetation dataset (see Table 3) was obtained according to the following stepwise procedure:

1. resampling data: to perform the habitat classification only on the natural woodland areas, a forest mask was generated to resample the vegetation plots. The mask was obtained by combining Copernicus Land Monitoring Service products, specifically the High-Resolution Layers Tree Cover Density (TCD, [67]), the Imperviousness [68], and the CORINE Land Cover [69]. All of the records outside the forest mask were excluded;

2. clustering data: from the whole dataset only forest habitats were extracted and clustered according to the EUNIS hierarchical classification nomenclature, following the EUNIS-ESy definitions [22]; and,

3. filtering data: all data assigned at more than one EUNIS codes (e.g., bias plots assignment of mixed forest that linked at two different EUNIS groups) and all data recorded with the same geographic coordinates (i.e., plots of re-surveying monitoring research activities) were also excluded. Finally, a visualization data test was performed to identify spatial mismatches errors and/or spatial bias occurrences.

\subsubsection{Predictor Variables}

A spatially explicit dataset of predictors was produced to generate classified habitat maps by the classification approach selected.

Dataset of predictors includes three main categories:

1. environmental data: variables related to geographic, topographic, climatic, and soil properties; 
2. spectral data: variables extracted from EO satellite sensors; and,

3. temporal data: variables representing temporal statistics and phenological metrics estimated from the biophysical index time series, generated from satellite EO data.

All of the variables were collected or calculated from dataset distributed under openaccess policy and spatially resampled at $20 \mathrm{~m}$ resolution. See Table A1 for a complete list of variables, with name, description, units, and data sources.

Reference spatial grid has been set to $20 \mathrm{~m}$ spatial resolution for the coordinate reference systems EPSG 32632 and EPSG 32633. The environmental variables were selected based on the relevance as drivers of plant distribution [55,70]. Among the geographic variables, the linear distance in $\mathrm{km}$ from both shoreline and river network were computed for each grid cell [71]. A digital elevation model [72] at $20 \mathrm{~m}$ spatial resolution was used to calculate elevation, slope, and aspect using a $3 \times 3$ pixel neighbourhood. Northerness and easterness components were later calculated form aspect, using sine or cosine transformation, in order to obtain continuous variables. The total rainfall [73] and average temperature [74] at $1 \mathrm{~km}$ resolution were interpolated from cell centroid coordinates to reference grid resolution using regularized spline with tension. The average temperature was normalized for the altitude effect [75]. Daily average solar irradiance was estimated at $20 \mathrm{~m}$ spatial resolution using the equations for computation of solar energy related parameters [76] and while considering local topography. Daily solar irradiance was aggregated to calculate monthly averages, and later daytime cloud cover collected from the ESA-Climate Change Initiative cloud dataset, for the period 2004-2014, were used to calculate the monthly average climatology cloud cover percentage [77]. Cloud cover percentage has been resampled to $20 \mathrm{~m}$ spatial resolution using regularized spline with tension and then used to weight solar irradiance with a factor of 0.75 , to account for sky-diffuse solar radiation on cloudy days [78]. Finally, monthly weighted solar irradiance was used to calculate daily average solar radiation. Datasets representing soil properties at $250 \mathrm{~m}$, specifically the soil organic carbon stock, $\mathrm{pH}$, and absolute depth to bedrock, were collected from the SoilGrids (see Table A1) repository and interpolated to reference grid resolution using a Bartlett filter with $750 \mathrm{~m}$ radius.

Spectral variables, specifically spectral reflectance bands and spectral indices, were calculated from EO data that were acquired by Multi-Spectral Instrument (MSI) sensor onboard Sentinel-2 satellites. MSI is a multispectral sensor with a high spatial resolution (10 m, $20 \mathrm{~m}$, and $60 \mathrm{~m}$ ), high revisit capability (five days with a two satellite constellations), an orbital swath width of $290 \mathrm{~km}$, and a spectral band set from the visible to shortwave infrared. Sentinel-2 MSI L2A data used for the analysis, distributed by Theia in MUSCATE format, represent the bottom of the atmosphere (BOA) reflectance, orthorectified, terrain-flattened, and atmospherically corrected with MACCS-ATCOR Joint Algorithm (MAJA) [79,80].

All of the satellite acquisitions of the period 2016-2019 with cloud cover lower than $90 \%$ were collected for the entire study area, for a total of around 26000 images distributed in 61 granules and corresponding to around 34 Terabyte (TB) of data stored. For each satellite image, all 10 surface reflectance spectral bands were first spatial resampled at $20 \mathrm{~m}$, to obtain a full consistent set of spectral bands, namely the B2 (blue), B3 (green), B4 (red), B5 (Red edge 1), B6 (Red edge 2), B7 (Red edge 3), B8 (NIR1), B8a (NIR2), B11 (SWIR1), and B12 (SWIR2). Later, pixels corresponding to clouds, cloud shadows, snow, and water in the product quality flag masks or corresponding to topographic shadows (identified by product quality flags representing the topographic mask and low-sun mask, with the latter considering the pixel aspect, slope, and sun zenith angle) were masked out from further analysis. Sentinel-2 MSI surface reflectance spectral bands for the period March-October have been used for the classification. Spectral information from satellite data sensed during late fall and winter period were not considered among the predictors, since they are often hampered by snow cover and topographic shadows, and they have already been demonstrated to have a scarce result on forest habitat detection [55]. However, temporal predictors included the winter period with seasonal statistics (i.e., average, maximum, 
and standard deviation), since they allowed for the distinction between evergreen and broadleaved forest patterns.

In addition to Sentinel-2 MSI spectral bands, four spectral indices were selected to account for green, red, and yellow photosynthetic leaf pigments, during flowering and senescence, which is the period when the plant is curtailing chlorophyll production revealing various accessory pigments [81] and, consequently, determining the starting of fall foliage (Table 2).

Table 2. Spectral indices adopted, equation with Sentinel-2 Multispectral Instrument (MSI) bands, and bibliographic references.

\begin{tabular}{ccc}
\hline Spectral Index & Equation & Reference \\
\hline Enhanced Vegetation Index EVI & $2.5 \times(B 8-B 4)$ & {$[82]$} \\
Normalized Difference Yellow Index NDYI & $(B 8+6 \times B 4-7.5 \times B 2+1)$ & {$[83]$} \\
Normalized Difference Red/Green Redness Index RI & $\frac{(B 3-B 2)}{(B 3+B 2)}$ & {$[84]$} \\
Carotenoid Reflectance Index CRI1 & $\frac{(B 4-B 3)}{(B 4+B 3)}$ & {$[85]$} \\
\hline
\end{tabular}

The Leaf Area Index (LAI), a biophysical index defined as half of the total green (i.e., photosynthetically active) leaf area per unit horizontal ground surface area, was estimated from the surface reflectance data using the biophysical processor [86] available in SNAP software version 7. Finally, for each spectral band and selected index, annual monthly averages were calculated from all of the available satellite images to produce the final set of spectral predictors.

Temporal variables were calculated from LAI time series, stacked in a large multidimensional datacube after applying an image co-registration step [87]. LAI time series were later temporally smoothed and daily interpolated using the procedure based on second order weighted polynomial fitting and the Whittaker smoothing, as described in [88]. LAI daily time series were used to calculate the annual (average, minimum, maximum, delta, standard deviation) and seasonal (winter and summer average, minimum, maximum) temporal statistics and to estimate phenological metrics using the method that is described in [89]. The phenological metrics have only been used as predictors for T1 classification (i.e., deciduous broadleaved), since plant phenology of evergreen plants has lower temporal fluctuation in terms of LAI values, which makes their estimation uncertain. Other studies attempted to use EO time series to describe plant phenology in vegetation mapping, without an in-depth exploitation through the phenological metrics estimates [90]. The median value of each temporal variable calculated for the years 2016-2019 has been selected as temporal predictor used for the training, validation and testing phases of the classification algorithm.

All of the procedures used to obtain the dataset of predictors were performed using GRASS GIS for the processing of environmental predictors, SNAP for the Sentinel-2 MSI data processing, and R software for the processing of temporal predictors.

\subsection{Classification}

\subsubsection{Predictors Selection}

The Pearson correlation coefficient and the variance inflation factor (VIF) among all variables were performed to test for multi-collinearity to reduce the high number of predictors and improve model accuracy removing redundancy. All of the predictors with a Pearson correlation coefficient higher than 0.7 and a VIF higher than 10 [91] were removed. R-package 'Boruta' [92] was used to test whether the remaining variables were correlated. Boruta is a wrapper algorithm around a Random Forest (RF) classification model, in which several runs of RF are performed to generate shadow features and test the significance of each variable, in order to confirm or reject them. Finally, RF [93] was used to investigate the importance of predictors and assess their contribution to the prediction of the response 
variable, through the calculation of the importance value and the Gini index. RF was executed with a default set of hyperparameters using the 'ranger' R-package [94], and selecting the variables on an expert-based decision. All of these steps were done for each RF model (see the following section). Finally, the variable selection procedure was amended, based on expert knowledge and scientific reference [29,50,95], in order to reconsider a few variables that have a high significance for the habitat detection (see Figure 4).

\subsubsection{Supervised Machine Learning Model}

For classifying all of the forest habitats, RF was used as supervised machine learning model [93], which has been successfully applied for classification purpose in the context of vegetation remote sensing (see Kattenborn et al. [52] for an exhaustive list of reference). $\mathrm{RF}$ is a decision tree algorithm and is currently the most popular ensemble method for classifying and predicting forest habitat types [96]. Because RF produced several independent trees by intensive resampling of different subset of predictors, it is natural to consider this adapted bootstrapping scheme for big data context [97]. In addition, in some studies of comparison between different classification algorithms, RF was found to be the most performing $[30,52,96,98]$, or at least comparable with other. Hence, when considering that the proposed study was not a comparison of classification methods, but a demonstrative procedure, the final choice was to apply the RF classifier. To build and grow trees, RF involves several hyperparameters that control both the structure of each individual tree (e.g., nodesize) and the structure and the size of the forest (e.g., mtry, ntree). Despite that it is well known that RF works reasonably well with the default set of hyperparameters, their tuning can improve the performance of RF [99]. R package ' $\mathrm{mlr}$ ' [100] was used to tune the best RF hyperparameters combination, evaluating the following value ranges: $m$ try from squared root of the number of variables predictors to the number of variables predictors minus 1; min.node.size from 1 to 3; and, ntree from 401 to 1001. The best set of hyperparameter was chosen selecting the higher Cohen's kappa coefficient calculated using five-fold cross-validation with 20 repetitions.

A two-stage hierarchical classification scheme using 'ranger' R-package [94] was built by training a total of 4 RF models, each one setup with a distinct set of predictors and hyperparameters. The first stage RF model classified EUNIS II level forest classes: deciduous broadleaved, evergreen broadleaved, and needleleaved (T1, T2, and T3, respectively). At the second stage, the other three RF models classified EUNIS III level for each EUNIS II class identified in the first stage.

Each RF model was trained using a stratified random sample of $70 \%$ of data, and the model performance was tested using the remaining 30\% (internal evaluation). The accuracy assessment of the procedure depends on a confusion matrix (error matrix) and the following accuracy measures derived from that: the Overall accuracy, the User's and Producer's accuracy, and their Standard error. The formulas to obtain the accuracy metrics and the standard error were presented in Stehman \& Foody, 2019 [101]. The computing of the Cohen's kappa was also made.

The trained RF models were applied to the selected sets of environmental, spectral, and temporal predictors in order to classify the forest habitat types for the entire Italian national territory. The Gini index was calculated to evaluate the importance of each predictor.

The model classification was spatialized for the entire Italian territory to produce maps of habitat forest types according to EUNIS II and III levels. An additional qualitative check of the obtained results was done by expert judgment and the validity/accuracy was confirmed.

\section{Results}

\subsection{Response Variable}

From the vegetation database, 14385 plots were selected and classified in 24 forest habitats according to the EUNIS III level: 12 broadleaved deciduous (T1), four broadleaved evergreen (T2), and eight needleleaved forest habitats (T3) (Table 3). 
Table 3. Selected habitat plots by expert system classification according to EUNIS code (II and III level).

\begin{tabular}{|c|c|c|c|}
\hline $\begin{array}{l}\text { EUNIS Code II } \\
\text { Level }\end{array}$ & $\begin{array}{l}\text { EUNIS Code III } \\
\text { Level }\end{array}$ & EUNIS 2020 Habitat Name & Records \\
\hline \multirow[t]{13}{*}{ T1 } & & Broadleaved Deciduous forest habitat-type & 8328 \\
\hline & $\mathrm{T} 11$ & Temperate Salix and Populus riparian forest & 1027 \\
\hline & $\mathrm{T} 15$ & Broadleaved swamp forest on non-acid peat & 772 \\
\hline & $\mathrm{T} 17$ & Fagus forest on non-acid soils & 2404 \\
\hline & $\mathrm{T} 18$ & Fagus forest on acid soils & 614 \\
\hline & T19 & Temperate and sub-mediterranean thermophilous deciduous forest & 1389 \\
\hline & T1A & Mediterranean thermophilous deciduous forest & 815 \\
\hline & $\mathrm{T} 1 \mathrm{~B}$ & Acidophilous Quercus forest & 147 \\
\hline & $\mathrm{T} 1 \mathrm{C}$ & $\begin{array}{l}\text { Temperate and boreal mountain Betula and P. tremula forest on } \\
\text { mineral soils }\end{array}$ & 32 \\
\hline & T1D & $\begin{array}{l}\text { Southern European mountain Betula and P. tremula forest on } \\
\text { mineral soils }\end{array}$ & 36 \\
\hline & $\mathrm{T} 1 \mathrm{E}$ & Carpinus and Quercus mesic deciduous forest & 260 \\
\hline & $\mathrm{T} 1 \mathrm{~F}$ & Ravine forest & 541 \\
\hline & T1G & A. cordata forest & 291 \\
\hline \multirow[t]{5}{*}{ T2 } & & Broadleaved Evergreen forest habitat-type & 3776 \\
\hline & $\mathrm{T} 21$ & Mediterranean evergreen Quercus forest & 3015 \\
\hline & $\mathrm{T} 22$ & Mainland laurophyllous forest & 145 \\
\hline & $\mathrm{T} 24$ & Olea europaea and Ceratonia siliqua forest & 492 \\
\hline & $\mathrm{T} 27$ & Ilex aquifolium forest & 124 \\
\hline \multirow[t]{9}{*}{ T3 } & & Needleleaved forest habitat-type & 2281 \\
\hline & $\mathrm{T} 31$ & Temperate mountain Picea forest & 412 \\
\hline & T32 & Temperate mountain Abies forest & 500 \\
\hline & $\mathrm{T} 33$ & Mediterranean mountain Abies forest & 98 \\
\hline & T34 & Temperate subalpine Larix, $P$. cembra and $P$. uncinata forest & 461 \\
\hline & T36 & $\begin{array}{c}\text { Temperate and sub-mediterranean montane } P \text {. sylvestris-P. nigra } \\
\text { forest }\end{array}$ & 295 \\
\hline & $\mathrm{T} 37$ & Mediterranean montane P. sylvestris-P. nigra forest & 84 \\
\hline & T3A & Mediterranean lowland to submontane Pinus forest & 365 \\
\hline & $\mathrm{T} 3 \mathrm{C}$ & Taxus baccata forest & 63 \\
\hline
\end{tabular}

The records are representative of natural forest cohorts existing on the Italian territory, according to Italian National Forestry Inventory [62]. The distribution of vegetation database is shown in Figure 3, according to the EUNIS II level classification. 

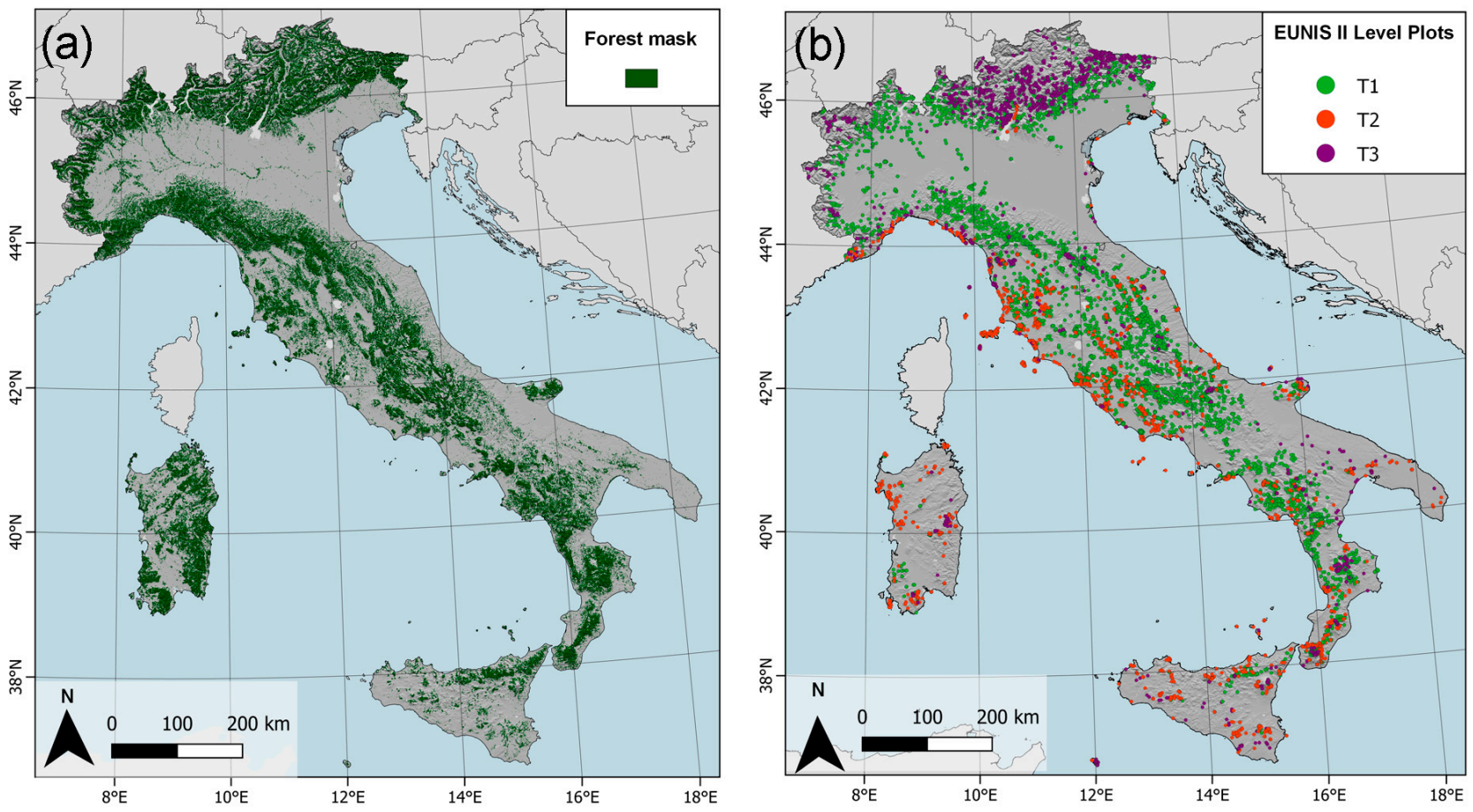

Figure 3. (a) Forest cover area corresponding to the forest mask produced in the ancillary data; (b) Spatial distribution of vegetation habitat dataset categorized in EUNIS II hierarchical level (T1: broadleaved deciduous; T2: broadleaved evergreen; and, T3: needleleaved forest habitat-type).

\subsection{Classification}

\subsubsection{Predictor Variables and Selection}

A set of 163 variables grouped in four categories has been used as predictors: 13 environmental variables (three geographic, four geomorphologic, three climatic, and three soil properties); 124 spectral variables (80 spectral bands, 44 spectral indices); and, 26 temporal variables (10 temporal statistics, 16 phenological metrics) (see Table A1 for the complete list). After the variable selection procedure, a total of 68 variables have been retained as predictors for the RF classification (see Figure 4). Successively, some of the predictors excluded in the previous step (i.e., elevation, normalized annual temperature, minimum value of LAI, maximum value of LAI, and latitude) were reconsidered in the classification procedure of the four RF models (see Figure 4). All of the selected variables reported a higher importance value than the shadow features generated by the Boruta algorithm. 


\begin{tabular}{|c|c|c|c|c|c|}
\hline Category & Variable & $\begin{array}{l}\text { EUNIS II } \\
\\
\text { Gini }\end{array}$ & $\begin{array}{l}\text { EUNIS III T1 } \\
\text { Gini }\end{array}$ & $\begin{array}{l}\text { EUNIS III T2 } \\
\text { Gini }\end{array}$ & $\begin{array}{r}\text { EUNIS III T3 } \\
\text { Gini }\end{array}$ \\
\hline \multirow{9}{*}{ 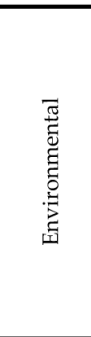 } & Latitude & 1287.04 & $3249.78^{*}$ & 212.79 & \\
\hline & Distance from shoreline (Log10) & 1037.19 & 1992.63 & 328.8 & 820.74 \\
\hline & Elevation & $598.51^{*}$ & $3094.17^{*}$ & 669.74 & \\
\hline & Slope & 97.01 & 984.6 & & 66.83 \\
\hline & Northerness & 60.75 & & 83.39 & 76.29 \\
\hline & Eastness & 53.7 & & 88.9 & \\
\hline & $\begin{array}{l}\text { Daily average solar radiation } \\
\text { Soilorganic carbon stock }\end{array}$ & 75.55 & 542.24 & 64.74 & 457.43 \\
\hline & $\mathrm{pH}$ index measured in water solution & 497.53 & 1960.61 & 392.06 & \\
\hline & Absolute depth to bedrock & 128.91 & 650.67 & 66.43 & 180.22 \\
\hline \multirow{3}{*}{ 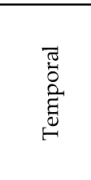 } & Annual minimum LAI & $103.77^{*}$ & & & \multirow[t]{2}{*}{$77.15^{*}$} \\
\hline & Annual maximum LAI & $62.24^{*}$ & & & \\
\hline & Annual standard deviation LAI & 567.06 & 463.27 & & $\begin{array}{l}93.4 \\
89.83\end{array}$ \\
\hline \multirow{38}{*}{$\begin{array}{l}\overline{\widetilde{E}} \\
\text { षूँ } \\
\text { कि }\end{array}$} & Sentinel-2 MSI B2 value at yearly month 04 & 47.42 & 298.81 & 50.44 & 46.03 \\
\hline & Sentinel-2 MSI B2 value at yearly month 05 & 46.83 & & 55.16 & 41.54 \\
\hline & Sentinel-2 MSI B2 value at yearly month 06 & 48.73 & & & \\
\hline & Sentinel-2 MSI B2 value at yearly month 07 & 40.06 & 595.62 & & 70.48 \\
\hline & Sentinel-2 MSI B2 value at yearly month 09 & 43.44 & 326.08 & & 48.08 \\
\hline & Sentinel-2 MSI B2 value at yearly month 10 & 52.59 & 370.09 & & 70.82 \\
\hline & Sentinel-2 MSI B6 value at yearly month 03 & 47.38 & & & \\
\hline & Sentinel-2 MSI B6 value at yearly month 05 & 118.38 & & & \\
\hline & Sentinel-2 MSI B6 value at yearly month 10 & 59.07 & & & \\
\hline & Sentinel-2 MSI B7 value at yearly month 04 & & & 64.07 & \\
\hline & Sentinel-2 MSI B7 value at yearly month 10 & & & 81.28 & \\
\hline & Sentinel 2 MSI B8 value at yearly month 03 & & & 78.18 & 43.17 \\
\hline & Sentinel-2 MSI B8A value at yearly month 04 & 76.76 & & & \\
\hline & Sentinel-2 MSI B11 value at yearly month 03 & 117.8 & & & \\
\hline & Sentinel-2 MSI B11 value at yearly month 06 & 50.95 & & 61.18 & \\
\hline & Sentinel-2 MSI EVI value at yearly month 03 & 153.76 & 578.15 & 158.79 & \\
\hline & Sentinel-2 MSI EVI value at yearly month 04 & & & & 68.07 \\
\hline & Sentinel-2 MSI EVI value at yearly month 05 & & & & 58.73 \\
\hline & Sentinel-2 MSI EVI value at yearly month 09 & 93.34 & 342.91 & & \\
\hline & Sentinel-2 MSI NDYI value at yearly month 03 & 42.01 & & 54.98 & \\
\hline & Sentinel-2 MSI NDYI value at yearly month 04 & 50.77 & 332.19 & & 87.78 \\
\hline & Sentinel-2 MSI NDYI value at yearly month 05 & & 434.37 & & \\
\hline & Sentinel-2 MSI NDYI value at yearly month 07 & 41.5 & & & \\
\hline & Sentinel-2 MSI NDYI value at yearly month 08 & 42.83 & & & \\
\hline & Sentinel-2 MSI NDYI value at yearly month 10 & & & & 81.67 \\
\hline & Sentinel-2 MSI RI value at yearly month 03 & 304.01 & 428.81 & 36.98 & 40.08 \\
\hline & Sentinel-2 MSI RI value at yearly month 04 & 54.07 & 419.26 & 89.24 & 65.54 \\
\hline & Sentinel-2 MSI RI value at yearly month 05 & 43.03 & 403.04 & & 63.35 \\
\hline & Sentinel-2 MSI RI value at yearly month 06 & 40.15 & & & 56.27 \\
\hline & Sentinel-2 MSI RI value at yearly month 07 & 42.15 & & & 58.32 \\
\hline & Sentinel-2 MSI RI value at yearly month 09 & 47.08 & 377.64 & & 70.12 \\
\hline & Sentinel-2 MSI RI value at yearly month 10 & 52.33 & 361 & & \\
\hline & Sentinel-2 MSI CRI1 value at yearly month 04 & & & 65.02 & \\
\hline & Sentinel-2 MSI CRI1 value at yearly month 05 & 49.33 & & 62.36 & \\
\hline & Sentinel-2 MSI CRI1 value at yearly month 06 & 46.25 & & 97.99 & 40.15 \\
\hline & Sentinel-2 MSI CRI1 value at yearly month 07 & & & & 53.41 \\
\hline & Sentinel-2 MSI CRI1 value at yearly month 09 & 49.03 & & 73.49 & \\
\hline & Sentinel-2 MSI CRI1 value at yearly month 10 & 83.63 & 439.93 & & \\
\hline
\end{tabular}

Figure 4. List of environmental, temporal and spectral predictors selected after multi-collinearity and expert-based analysis for each EUNIS II and III hierarchical level. Gini index values are reported for each Random Forests (RF) model: EUNIS II; T1 = Broadleaved Decidous; T2 = Breoadleaved Evergreen; T3 = Needleleaved. Colored bars represent the variable importance ranking, based on the Gini index value. Only variables with colored bars were selected as predictors in the model. * reconsidered variable through expert-based selection procedure.

\subsubsection{Supervised Machine Learning Model}

From the five-fold cross-validation tuning with 20 repetitions, the selected hyperparameters for the EUNIS II level classification were: mtry $=20$; num.trees $=908$; min.node.size $=2$. For the EUNIS III level classification, a different hyperparameters set has been tuned for each EUNIS II level class. For the T1 classification, the mtry was set to 24, the num.trees 
was set to 989, and the min.node.size was set to 3; for the T2 classification, the mtry was set to 16 , the num.trees was set to 527 , and the min.node.size was set to 2; and, for the T3 classification, the mtry was set to 15 , the num.trees was set to 981 , and the min.node.size was set to 2 .

The forest habitat types classification, using the RF modelling approach based on all input records (i.e., response variable) and including the variables selected (i.e., predictor variables), achieved an overall accuracy of $87 \%$ at the EUNIS II level classes (i.e., T1, T2, and T3). The highest misclassification was found between the broadleaved deciduous and the broadleaved evergreen habitat-type forests. The three EUNIS II level classes of forest (broadleaf and conifer forest) achieved very high producer's and user's accuracies ( $>85 \%$; see Table 4).

Table 4. Confusion matrix of RF result for the EUNIS II level classification. T1: broadleaved deciduous forest habitat-type, T2: broadleaved evergreen forest habitat-type, T3: needleleaved forest habitat-type. OA: Overall Accuracy, PA: Producer's Accuracy, UA: User's Accuracy, SE: Standard Error.

\begin{tabular}{cccccc}
\hline \multirow{2}{*}{ Map Class } & \multicolumn{5}{c}{ Reference Class } \\
\cline { 2 - 6 } & T1 & T2 & T3 & Sum & UA (SE) \\
\hline T1 & 1037 & 80 & 63 & 1180 & $89.9(0.00)$ \\
T2 & 93 & 564 & 0 & 657 & $87.6(0.01)$ \\
T3 & 23 & 0 & 162 & 185 & $72(0.02)$ \\
\hline Sum & 1153 & 644 & 225 & OA (SE) $87.2 \%(0.75)$ \\
\hline PA (SE) & $87.9(0.00)$ & $85.8(0.03)$ & $87.6(0.13)$ & Kappa 0.77 \\
\hline
\end{tabular}

The second stage of habitat-type classification has been performed at EUNIS III hierarchical level, achieving an overall accuracy of $76.14 \%$. The highest overall accuracy was the one of the broadleaved evergreen forest, equal to $91 \%$, followed by $76 \%$ and $68 \%$ for needleleaved and broadleaved deciduous habitat forests, respectively (see Tables 5-7). Within the broadleaved evergreen habitat type classes, the mainland laurophyllous forest (EUNIS III T2) obtained the lowest classification accuracy $(29.4 \%)$, and its highest misclassification was with the Mediterranean evergreen Quercus forest; instead, regarding the Mediterranean evergreen Quercus forest, a user's accuracy of $96.5 \%$ was achieved (see Table 5). The needleleaved forest (EUNIS II T3) classes were, on average, well classified; indeed, the user's accuracy was higher than $65 \%$ for each class. On the contrary, classes of broadleaved deciduous forests (EUNIS II T1) were classified worst: six classes had a user's accuracy below 50\%, three classes had a user's accuracy between $50 \%$ and $60 \%$, and only three classes had a user's accuracy higher than $60 \%$.

Table 5. Confusion matrix of RF result for the broadleaved deciduous forest habitat-type EUNIS III level classification. T11: temperate Salix and Populus riparian forest, T15: broadleaved swamp forest on non-acid peat, T17: Fagus forest on non-acid soils, T18: Fagus forest on acid soils, T19: temperate and submediterranean thermophilous deciduous forest, T1A: mediterranean thermophilous deciduous forest, T1B: acidophilous Quercus forest, T1C: temperate and boreal mountain Betula and Populus tremula forest on mineral soils, T1D: southern european mountain Betula and P. tremula forest on mineral soils, T1E: Carpinus and Quercus mesic deciduous forest, T1F: ravine forest, T1G: A. cordata forest. OA: Overall Accuracy, PA: Producer's Accuracy, UA: User's Accuracy, SE: Standard Error.

\begin{tabular}{ccccccccccccccc}
\hline \multirow{2}{*}{$\begin{array}{c}\text { Map } \\
\text { Class }\end{array}$} & T11 & T15 & T17 & T18 & T19 & T1A & T1B & T1C & T1D & T1E & T1F & T1G & Sum & UA (SE) \\
\hline T11 & 36 & 4 & 1 & 1 & 6 & 1 & 4 & 0 & 0 & 2 & 2 & 0 & 57 & $50.7(0.06)$ \\
T15 & 5 & 22 & 1 & 2 & 0 & 1 & 0 & 0 & 0 & 0 & 0 & 0 & 31 & $55(0.08)$ \\
T17 & 6 & 3 & 357 & 22 & 27 & 2 & 5 & 3 & 0 & 0 & 20 & 4 & 449 & $85.6(0.02)$ \\
T18 & 1 & 0 & 16 & 17 & 0 & 0 & 1 & 1 & 0 & 1 & 1 & 0 & 38 & $37.8(0.08)$ \\
\hline
\end{tabular}


Table 5. Cont

\begin{tabular}{|c|c|c|c|c|c|c|c|c|c|c|c|c|c|c|}
\hline \multirow{2}{*}{$\begin{array}{l}\text { Map } \\
\text { Class }\end{array}$} & \multicolumn{14}{|c|}{ Reference Class } \\
\hline & T11 & T15 & T17 & T18 & T19 & T1A & T1B & T1C & T1D & T1E & T1F & T1G & Sum & UA (SE) \\
\hline T19 & 13 & 6 & 20 & 0 & 206 & 54 & 2 & 0 & 3 & 17 & 8 & 6 & 335 & $73.3(0.03)$ \\
\hline T1A & 6 & 0 & 3 & 0 & 30 & 87 & 0 & 0 & 0 & 1 & 1 & 2 & 130 & $58.8(0.04)$ \\
\hline T1B & 3 & 1 & 2 & 0 & 2 & 0 & 9 & 0 & 0 & 2 & 2 & 0 & 21 & $39.1(0.11)$ \\
\hline T1C & 0 & 0 & 1 & 1 & 0 & 0 & 1 & 2 & 0 & 0 & 1 & 0 & 6 & $33.3(0.21)$ \\
\hline T1D & 0 & 0 & 0 & 0 & 1 & 0 & 0 & 0 & 2 & 0 & 0 & 0 & 3 & $40(0.33)$ \\
\hline T1E & 0 & 1 & 0 & 0 & 2 & 0 & 1 & 0 & 0 & 5 & 1 & 0 & 10 & $16.1(0.10)$ \\
\hline T1F & 0 & 3 & 6 & 2 & 4 & 1 & 0 & 0 & 0 & 3 & 11 & 0 & 30 & $23.4(0.09)$ \\
\hline T1G & 1 & 0 & 10 & 0 & 3 & 2 & 0 & 0 & 0 & 0 & 0 & 20 & 36 & $62.5(0.08)$ \\
\hline Sum & 71 & 40 & 417 & 45 & 281 & 148 & 23 & 6 & 5 & 31 & 47 & 32 & OA (S & $67.6 \%(1.50)$ \\
\hline $\begin{array}{c}\text { PA } \\
\text { (SE) }\end{array}$ & $\begin{array}{c}63.2 \\
(0.16)\end{array}$ & $\begin{array}{c}71 \\
(1.23)\end{array}$ & $\begin{array}{l}79.5 \\
(0.00)\end{array}$ & $\begin{array}{l}44.7 \\
(0.23)\end{array}$ & $\begin{array}{l}61.5 \\
(0.01)\end{array}$ & $\begin{array}{c}66.9 \\
(0.07)\end{array}$ & $\begin{array}{c}42.9 \\
(0.69)\end{array}$ & $\begin{array}{c}33.3 \\
(0.78)\end{array}$ & $\begin{array}{c}66.7 \\
(13.03)\end{array}$ & $\begin{array}{c}50 \\
(0.77)\end{array}$ & $\begin{array}{c}36.7 \\
(0.26)\end{array}$ & $\begin{array}{c}55.6 \\
(0.65)\end{array}$ & & pa 0.57 \\
\hline
\end{tabular}

Table 6. Confusion matrix of RF result for the broadleaved evergreen forest habitat type EUNIS III level classification. T21: mediterranean evergreen Quercus forest, T22: mainland laurophyllous forest, T24: Olea europaea-Ceratonia siliqua forest, T27: Ilex aquifolium forest. OA: Overall Accuracy, PA: Producer's Accuracy, UA: User's Accuracy, SE: Standard Error.

\begin{tabular}{ccccccc}
\hline \multirow{2}{*}{ Map Class } & \multicolumn{7}{c}{ Reference Class } \\
\cline { 2 - 7 } & T21 & T22 & T24 & T27 & Sum & UA (SE) \\
\cline { 2 - 7 } T21 & 551 & 12 & 19 & 4 & 586 & $96.5(0.01)$ \\
T22 & 4 & 5 & 0 & 0 & 9 & $29.4(0.18)$ \\
T24 & 11 & 0 & 29 & 0 & 40 & $60.4(0.07)$ \\
T27 & 5 & 0 & 0 & 4 & 9 & $50(0.18)$ \\
\hline Sum & 571 & 17 & 48 & 8 & OA (SE) $91.5 \%(1.12)$ \\
\hline PA (SE) & $94(0.00)$ & $55.6(3.44)$ & $72.5(0.57)$ & $44.4(4.17)$ & Kappa 0.55 \\
\hline
\end{tabular}

Table 7. Confusion matrix of RF result for the needleleaved forest habitat type EUNIS III level classification. T31: temperate mountain Picea forest, T32: temperate mountain Abies forest, T33: mediterranean mountain Abies forest, T34: temperate subalpine Larix, P. cembra and P. uncinate forest, T36: temperate and sub-mediterranean montane P. sylvestris-P. nigra forest, T37: mediterranean montane P. sylvestris-P. nigra forest, T3A: mediterranean lowland to submontane Pinus forest, T3C: T. baccata forest. OA: Overall Accuracy, PA: Producer's Accuracy, UA: User's Accuracy, SE: Standard Error.

\begin{tabular}{|c|c|c|c|c|c|c|c|c|c|c|}
\hline \multirow{2}{*}{$\begin{array}{l}\text { Map } \\
\text { Class }\end{array}$} & \multicolumn{10}{|c|}{ Reference Class } \\
\hline & T31 & T32 & T33 & T34 & T36 & T37 & T3A & T3C & Sum & UA (SE) \\
\hline T31 & 44 & 17 & 0 & 4 & 0 & 0 & 0 & 0 & 65 & $67.7(0.06)$ \\
\hline T32 & 9 & 46 & 0 & 2 & 6 & 0 & 0 & 0 & 63 & $65.7(0.06)$ \\
\hline T33 & 0 & 0 & 21 & 0 & 0 & 1 & 2 & 1 & 25 & $84(0.07)$ \\
\hline T34 & 8 & 3 & 0 & 25 & 1 & 0 & 0 & 0 & 37 & $73.5(0.08)$ \\
\hline T36 & 3 & 4 & 0 & 3 & 34 & 0 & 0 & 0 & 44 & $75.6(0.06)$ \\
\hline T37 & 0 & 0 & 1 & 0 & 0 & 10 & 0 & 1 & 12 & $90.9(0.11)$ \\
\hline T3A & 1 & 0 & 3 & 0 & 4 & 0 & 53 & 1 & 62 & $94.6(0.05)$ \\
\hline T3C & 0 & 0 & 0 & 0 & 0 & 0 & 1 & 10 & 11 & $76.9(0.09)$ \\
\hline Sum & 65 & 70 & 25 & 34 & 45 & 11 & 56 & 13 & OA (SI & $.2 \%(5.86)$ \\
\hline PA (SE) & $67.7(0.04)$ & $73(0.04)$ & $84(0.04)$ & $67.6(0.11)$ & $77.3(0.09)$ & $83.3(0.36)$ & $85.5(0.31)$ & $90.9(0.19)$ & & 0.72 \\
\hline
\end{tabular}

Overall, the environmental variables were, by far, the most important factor for explaining the classification of the forest habitat-types, regardless of the EUNIS level. The variables exhibiting higher Gini index values for the EUNIS II level classification were: latitude; distance from shoreline; elevation; annual standard deviation LAI; pH index; Sentinel-2 MSI spectral index RI value at yearly month 03; annual cumulated rainfall; annual delta LAI; Sentinel-2 MSI spectral index EVI value at yearly month 03; and, absolute depth to bedrock (see Figure 4). For the two broadleaved classification at EUNIS III level (T1 and T2), the most important variables were: latitude; distance from shoreline (Log10); 
elevation; $\mathrm{pH}$ index; and, annual cumulated rainfall. The variables with high Gini index values were latitude and distance from river network for T1 and T2 forest habitat-types, respectively (see Figure 4). Even for the T3 habitat-type EUNIS III level classification, the most important variables were: distance from shoreline; soil organic carbon stock; annual cumulated rainfall and normalized annual average air temperature; Sentinel-2 MSI LAI value at yearly month 05 ; absolute depth to bedrock; annual standard deviation LAI; and, distance from river network (see Figure 4).

The following figures show the results of the projected classified map of forest habitat for the entire of Italy (Figure 5) and at local resolution (Figure 6), within the forest mask at the EUNIS III level T1-3. Figure A1 also shows pictures of woodland landscapes according to: T1 Broadleaved Deciduous (Figure A1 panel a); T2 Broadleaved Evergreen (Figure A1 panel b); and, T3 needleleaved forest habitat type (Figure A1 panel c). Finally, of the 240 million pixels potentially detectable (spatial extension of the Forest Mask layer), approximately $9.15 \%$ was not classified. Most of the area not classified were distributed on mountainous regions.

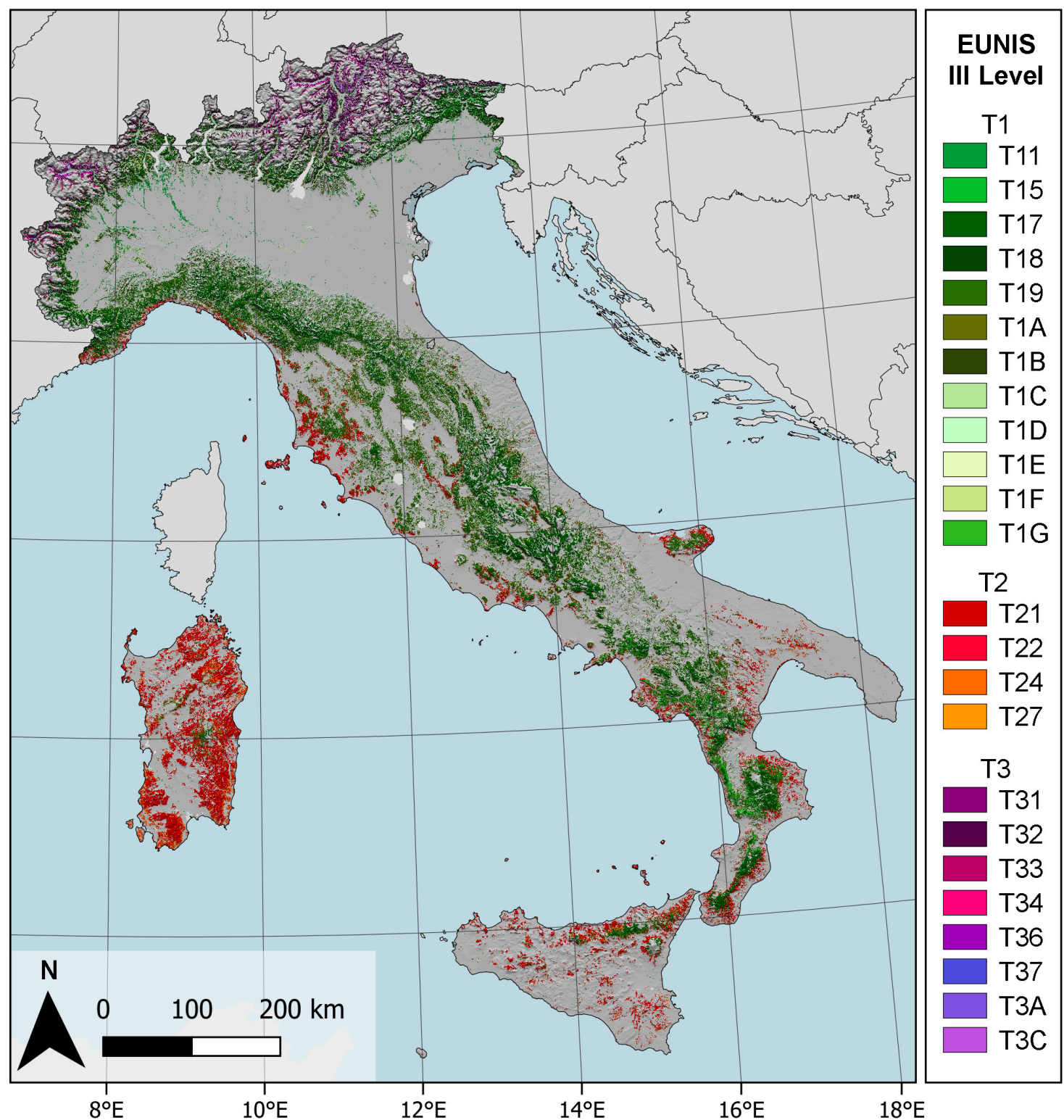

Figure 5. Forest habitat map of Italy from RF at EUNIS III level classification. The color legend format follows Pedrotti 2012 [102]. For the code reference of the legend, see Table 3. 

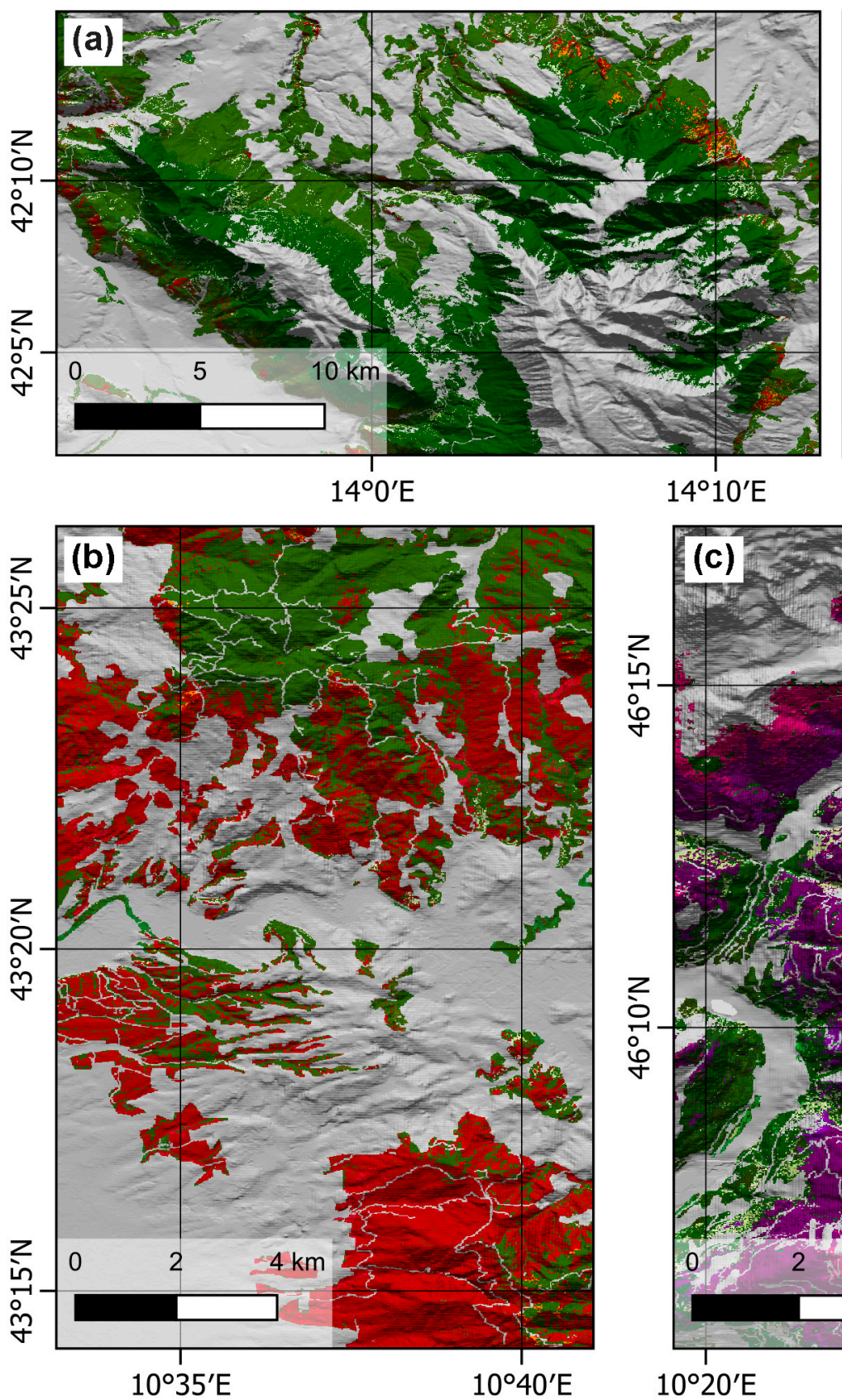
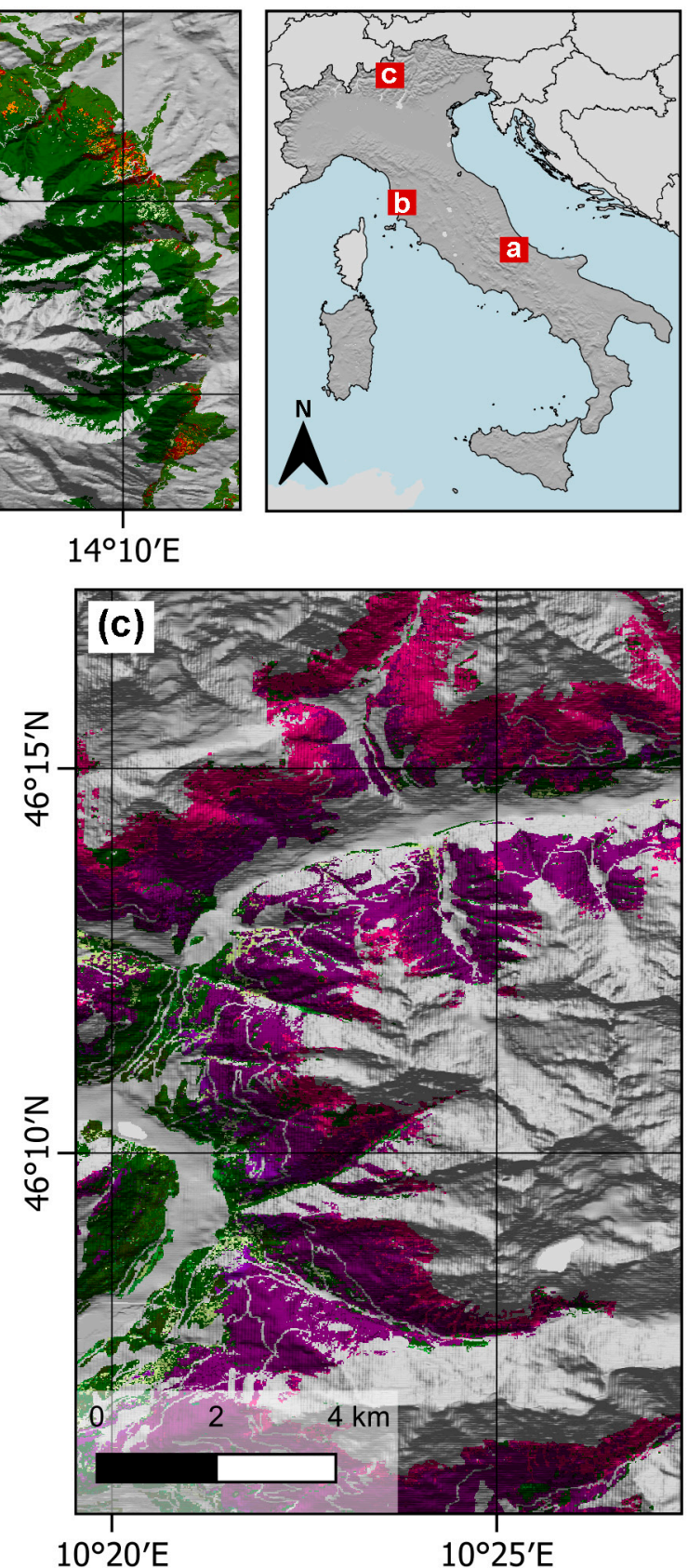

EUNIS
III Level

T1

T11

$\mathrm{T} 15$

$\mathrm{T} 17$

T18

T19

T1A

T1B

$\mathrm{T} 1 \mathrm{C}$

T1D

T1E

T1F

T1G

T2

T21

T22

T24

T27

T3

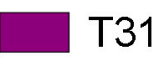

T32

T33

T34

T36

T37

T3A

T3C

$10^{\circ} 20^{\prime} \mathrm{E}$

\section{$10^{\circ} 25^{\prime} \mathrm{E}$}

Figure 6. Local spatial extent of: (a) T1 broadleaved deciduous forest on central Italy; (b) T2 broadleaved evergreen forest along Tyrrhenian coast on central Italy; and, (c) T3 needleleaved forest habitat in the Alps on northern Italy. For the code reference of the legend, see Table 3.

\section{Discussion}

This study proposed an approach to map forest habitats according to EUNIS classification (II and III levels), when considering the great habitat variability of the study area, in order to support the elaboration of conservation strategies and the environmental assessment. It combined nationwide biodiversity database, environmental information, and satellite EO data (Sentinel-2 MSI at $20 \mathrm{~m}$ spatial resolution) to train a supervised machine learning model for forest habitat classification. Previous studies on forest habitat mapping in Italy used satellite data for classification at coarse spatial and thematic resolutions, often investigating small areas (regional or sub regional scale areas) $[37,90,103]$ or focusing on single tree species [96]. 
Spectral and temporal features from Sentinel-2 MSI big datacubes were fully exploited in order to generate spectral and temporal predictor dataset (e.g., the estimation of phenological metrics). Such predictors dataset, combined with geomorphological, climate, and pedological variables, allowed for training a supervised machine learning model using a two-stages hierarchical classification scheme.

A potential feature of the current study concerns the updatability of the approach proposed, which allows for the habitat maps to be updated using EO temporal predictors, providing a dynamic and key contribution to ecological monitoring and assessment. The change detection metrics derived from the proposed procedure could be relevant for environmental issues, having a strong impact on the conservation status of habitats [104]. The approach can also improve predictive distribution models of endangered animal species, which are based on the use of high resolution EO data to identify fine-scale habitat features [105]. Moreover, it could be useful to evaluate the effects of global changes on resilience and species composition of habitats [106]. When considering that Sentinel-2 satellite mission systematically acquires data worldwide over land, the proposed approach can be reproduced and extended to all of the vegetated geographical areas in the earth, thanks to the existing high resolution layers (i.e., Copernicus product) [44] and the availability of plant species archive (i.e., EVA) [17]. Moreover, in the absence of high resolution land cover and thematic maps, they could be generated from the time series analysis of satellite derived vegetation indices (e.g., NDVI, EVI, and LAI). The evaluation of the importance of the predictor categories used for the classification models was one of the scopes of this research. Using the VIF and correlation analyses, a reduced set of predictors was selected to remove the high multi-collinearity for each classification model (see Table A2). The spectral predictors that result in a higher importance for discriminating forest habitats are those related to plant greening (Sentinel-2 MSI EVI value at yearly month 04, Sentinel-2 MSI B2 and B12 value at yearly month 03), flowering and browning (Sentinel-2 MSI NDYI value at yearly month 04,05 , and 10 , Sentinel-2 MSI RI value at yearly months 03,04 , and 10). This result confirms that the spring and fall seasons show the highest heterogeneity of radiometric signals due to the variability on vegetation growing and senescing pattern along the altitudinal and latitudinal gradients in Italy. Among the spectral bands, B2 (blue) showed the greater Gini index values and resulted in being more frequently selected among the predictors than other spectral bands, while the redness indices (RI and CRI1) were the spectral indices with higher Gini index values and more frequently selected.

LAI biophysical information was selected as variable for the estimation of temporal predictors. Apart from its reduced saturation in forest sites as compared to spectral indices (e.g., NDVI) [107], LAI derived predictors played a key role in the forest habitats discrimination. In fact, its derived temporal statistics resulted in high importance values within the classification model (annual standard deviation LAI, annual delta LAI, and Sentinel-2 MSI LAI value at yearly month 05), being even higher than single spectral predictors.

Overall, this study demonstrates the suitability of the Sentinel-2 MSI derived information for the separability of broad cover forest habitat types (i.e., EUNIS II level, based on plant functional traits), as well as for the identification of detailed EUNIS classification types (i.e., III level), based on their ecological features (i.e., species composition) [55].

The Gini index confirms how the environmental predictors remarkably contribute to the final habitat classification (see also [58]), for both the EUNIS II and III levels (see Table A2) $[29,108]$. In terms of explanatory variable importance, the results show how the variability of climatic and geographic pattern of the Italian territory play a paramount role in affecting the plant community trait responses and, consequently, determining a wide diversity of forest habitat types along the peninsula, which includes some of most important forest ecosystems in southern Europe (i.e., the Mediterranean biogeographical region) [109]. The high elevation-relief ratio between elevation versus distance from the shoreline, and the presence of high mountain ranges (i.e., reaching a maximum of over $2500 \mathrm{~m}$ for the Apennine and 4500 in the Alps), are all considered to be determining 
factors that affect the bio-climate in Italy (i.e., from Mediterranean to Alpine through the Continental climate zones) [110]. According to the hypotheses that was proposed by Miller \& Franklin [50] regarding the proportional increasing of importance of the topo-climatic variables with the increasing of study area and pixels grain size, a different importance weight between environmental and spectral predictors was observed. However, looking at the predictors importance at EUNIS II level of classification, our results show that the information related to plant phenology (leaf longevity, greening, flowering, browning, and leaf senescence) estimated from EO spectral and temporal predictors plays an important role in the separability of broadleaved deciduous, broadleaved evergreen, and needleleaved forests, according to [108].

The mismatching between the classified pixels and not classified pixels along the mountain ranges are due to the undetermined values of spectral variables, where cloud cover and shadows are affected by both topographic (i.e., slope and aspect) and climate conditions [111].

The results of classified tiles show an underestimation of needleleaved forests in central and southern Italy (see panel a of Figure 6), where most of them are afforested areas not available in the vegetation database (see Table 3). The natural distribution of native conifer forests in central and southern Italy is limited by environmental and climatic conditions and it often overlaps the broadleaved forests belts [112].

In the Apennine needleleaved forests, there are scarce data on the impact of forestation/afforestation on the indigenous stands (eg. forests of P.pinea, P.halepensis, P. nigra, and Picea abies in northern Apennine), with the exception of the well-known natural mixed coniferous-broadleaved forests $[113,114]$, such as the woods with European silver fir (A. $a l b a)$ in southern Italy, or Bosnian Pine (P. heldeeicrii) in the southernmost western part of the peninsula. Indeed, afforested stands are excluded from most of the surveys from botanists compiling biogeographic archives, thus determining a geographical bias $[30,115]$ with an underestimation of the afforested coniferous stands in the Apennine. Conversely, in the Alps (see panel c of Figure 6), the high contribution of vegetation surveys on forest consortia dominated by native tree species of Firs, Larches, and Pines, the low impact of forestation/afforestation activities, give a more accurate classification. Moreover, the evident discrepancy of data that are available for the semi-automatic classification (i.e., response variable) can also be seen in Table 3, where, out of a total of 2281 plots of coniferous forest, only the $24 \%$ are within the Mediterranean biogeographical regions (i.e., most of all the Apennine mountain chain).

The classification of the 24 forests habitat-types revealed different results for each of the EUNIS II level classes. The overall accuracy for the detection of tree species distribution with spectral indices analysis, obtained within the T2 $(91.5 \%)$ and T3 $(76.2 \%)$, is in line with similar studies [55]. The low (67.6\%) overall accuracy within T1 EUNIS III classes, is confirmed by previous studies, where the accuracy of the broadleaved deciduous species was always below of the broadleaved evergreen and coniferous forests [55].

The performance of habitat detection using EUNIS classification based on the stepwise approach of pre-defined hierarchical habitat schemes demonstrates that the mismatching between categories depends solely on ecological and biogeographic factors that reflects the real altitudinal gradient and coexistence in natural woodlands in southern Europe, thus revealing a good predicting capability of the method [116].

The misclassification in the confusion matrix of broadleaved deciduous (T1, Table 4) and evergreen (T2) forests (at the EUNIS II level) is mainly due to the similar ecological drivers and partial overlapping pattern at the edge of their own distribution, determining mixed forests along the elevation belt. The same driver on altitudinal contacts acts for the needleleaved forests that partially mismatch the broadleaved deciduous forests on the Alpine chain. Natural forests clearly reflected this condition. In the Apennines, the driver (ecological filtering on biogeographical pattern, see "Species Pool" theory) is different, but the results in detection capability are similar. Coniferous forests are relics [114], because of historical and biogeographic transformation, and the needleleaved trees are enveloped 
in broadleaved forests (F. sylvatica), again mismatching the net detection between the two categories.

The natural elevation pattern also explains the highest misclassification found between the broadleaved deciduous and broadleaved evergreen habitat-types at the III level of EUNIS classification (Tables 5 and 6). In needleleaved forest stands, Mediterranean and temperate coniferous trees show a net separability in forest classification as the result of a clear distinct chorological and ecological pattern, thus reflecting the quite different species composition (Table 7). Otherwise, Larix forest, the only deciduous conifer, was well classified (UA $73.5 \%$ and PA $67.6 \%$ ). The misclassification with temperate mountain Picea forest is explained by ecological and altitudinal overlapping of the two habitats, while the coexistence with temperate and sub-mediterranean montane $P$. sylvestris-P. nigra forest is frequent on stone slopes. Another justification of the misclassification of RF results could be the "class imbalances", as proposed by other researchers [30,55]. The EUNIS detection can be affected by the class with more samples, which is preferred by the RF classifier and, consequently, highlights the importance of an equilibrate sample design $[116,117]$. However, when a research includes several targets and refers to a wide extent, the only database available is collected from different sources over a large span of time, and it is difficult to manage (i.e., resampling thematic plots versus geographic). Moreover, in practice, some habitat-types often bring about mixed stands (i.e., see "Coexistence Theory") with others, and it is difficult to detect at fine spatial resolution data.

The results suggest that further pathways, to overcome some weaknesses shown, will aim to: (i) increase the EUNIS habitat categories to be mapped (i.e., grasslands, shrubs, wetlands, and coastal area); (ii) amplify the geographical extent to a wider area (i.e., from national to continental scale), obtain homogeneous classification within single biome unit (i.e., Mediterranean Basin); (iii) test different semi-supervised machine learning algorithms (e.g., Convolutional Neural Network, [118]) to obtain a more suitable habitat classification; and, (iv) also consider C-band Synthetic Aperture Radar (SAR) satellite data as candidate predictors for habitat classification purposes (e.g., forest canopy structure [119]).

\section{Conclusions}

Data-driven decisions are increasingly emerging as a turning point for policy makers. Sound scientific evidence and the availability of reliable and replicable data are key elements supporting informed decisions. In accordance with the renewed European Union ambition settled in the European Green Deal and in the targets of the 2030 Biodiversity Strategy, to protect nature as a whole, and strictly protect forests, the procedure presented here can contribute to detect forest types and changes over time and space, thus enhancing their conservation and restoration.

The combination of EO data, observing and measuring ecosystem processes, big data analytics, making use of advanced computational analytic techniques. like RF machine learning algorithm, allowed for demonstrating the applicability of up-to-date technologies for habitats classification. To this end, an operational example of how EO processing chains can support forest habitats assessment and monitoring is attempted in this paper. Several studies on habitat mapping by remote sensing products at the regional or sub-regional scale are available, but this is a first attempt to map EUNIS forest habitat-types in Italy at the national scale with the integration of nationwide biodiversity databases.

The approach presented here will allow an information technology procedure to be sped up with annual or seasonal updating, depending on the extension of the study area and the monitoring objectives. The obtained procedures could be applied on several environmental data in order to cyclically and promptly repeat spatial analysis to detect changes in space and time in support of ecosystem conservation issues, especially to evaluate the impact of illegal actions (e.g., forest harvesting) or natural hazards (e.g., destructive storms or other natural disasters) on habitat distribution.

Author Contributions: E.A. and F.F. conceived, framed and developed the whole research design; A.P. and A.O. implemented the methodological and analytical framework; L.C. contributed to 
conceptualization and interpreted the results; E.A. and A.P. have written the manuscript with the assistance of F.F. and L.C.; D.S. significantly contributed to the manuscript draft review; F.A. managed the data collection from European Vegetation Archive; A.T. supervised the project and acquired the research funds; E.A., F.F., A.P., L.C., F.A., D.S. and A.T. writte-review and edited the final text. All authors have read and agreed to the published version of the manuscript.

Funding: This manuscript is not funded by a specific project grant.

Institutional Review Board Statement: Not applicable.

Informed Consent Statement: Not applicable.

Acknowledgments: The authors want to acknowledge the Italian Institute for Environmental Protection and Research (ISPRA) that under the research agreement with the Italian Space Agency (ASI) "Habitat Mapping project" helped in achieving the goals of this study. The authors are also grateful to the useful and constructive comments and the support by ISPRA and academic colleagues: Roberto Inghilesi, Nicola Lugeri, Stefano Steri, Diana Aponte, Nicola Alessi and Borja Jiménez-Alfaro. Moreover, we would acknowledge the independent researchers on the development of free and open-source software for supporting the sharing of knowledge.

Conflicts of Interest: The authors declare no conflict of interest.

\section{Appendix A}

Table A1. List of variables used as predictors for the analysis of forest habitat types classification. River network and shoreline used to calculate distance from shoreline and distance from river network was MATTM National Geoportal (http:/ / www.pcn.minambiente.it/mattm/catalogo-metadati/, accessed on 12 January 2020); the source for soil properties variables was SoilGrids (https: / / soilgrids.org, accessed on 16 January 2020); the source for all the others predictors was ISPRA Database (http:/ / www.sinanet.isprambiente.it/it/sia-ispra, accessed on 28 January 2020).

\begin{tabular}{|c|c|c|c|c|}
\hline CATEGORY & SUBCATEGORY & NAME & DESCRIPTION & UNITS \\
\hline \multirow{4}{*}{ Environmental } & Geographic & $\begin{array}{l}\text { Lat } \\
\text { dCoastLog } \\
\text { dRivLog }\end{array}$ & $\begin{array}{c}\text { Latitude } 20 \text { m cellcentroid } \\
\text { Distance from shoreline }(\log 10) \\
\text { Distance from river network }(\log 10)\end{array}$ & $\begin{array}{l}\text { Degrees } \\
\mathrm{km} \\
\mathrm{km}\end{array}$ \\
\hline & Geomorphologic & $\begin{array}{l}\text { Elev } \\
\text { Slope } \\
\text { NorthN } \\
\text { EastN }\end{array}$ & $\begin{array}{c}\text { Elevation } \\
\text { Slope } \\
\text { Northerness } \\
\text { Eastness }\end{array}$ & $\begin{array}{c}\text { m a.s.l. } \\
\text { degrees } \\
\text { Polar units } \\
\text { Polar units }\end{array}$ \\
\hline & Climatic & $\begin{array}{l}\text { TannNorm } \\
\text { CRFann } \\
\text { sRad }\end{array}$ & $\begin{array}{c}\text { Normalized annual average air temperature } \\
\text { Annual Cumulated Rainfall } \\
\text { Daily average solar radiation }\end{array}$ & $\begin{array}{c}\text { Celsius degrees } \\
\mathrm{mm} / \text { year } \\
\mathrm{WH} / \mathrm{m}^{2}\end{array}$ \\
\hline & Soil properties & $\begin{array}{l}\text { ORCDRC } \\
\text { PHIHOX } \\
\text { BDTICM }\end{array}$ & $\begin{array}{c}\text { Soil organic carbon stock } \\
\mathrm{pH} \text { index measured in water solution } \\
\text { Absolute depth to bedrock }\end{array}$ & $\begin{array}{l}\text { permille } \\
\mathrm{pH} \\
\mathrm{cm}\end{array}$ \\
\hline Temporal & Temporal statistics & $\begin{array}{l}\text { LAI_min } \\
\text { LAI_avg } \\
\text { LAI_max } \\
\text { LAI_std } \\
\text { LAI_delta } \\
\text { LAI_djf_min } \\
\text { LAI_djf_avg } \\
\text { LAI_djf_max } \\
\text { LAI_jja_avg } \\
\text { LAI_jja_max }\end{array}$ & $\begin{array}{c}\text { Annual minimum LAI } \\
\text { Annualaverage LAI } \\
\text { Annual maximum LAI } \\
\text { Annual standard deviation LAI } \\
\text { Annual delta LAI } \\
\text { Winter (December, January, February) } \\
\text { minimum LAI } \\
\text { Winter (December, January, February) average } \\
\text { LAI } \\
\text { Winter (December, January, February) } \\
\text { maximum LAI } \\
\text { Summer (June, July, August) average LAI } \\
\text { Summer (June, July, August) maximum LAI }\end{array}$ & $\begin{array}{l}\mathrm{m}^{2} / \mathrm{m}^{2} \\
\mathrm{~m}^{2} / \mathrm{m}^{2} \\
\mathrm{~m}^{2} / \mathrm{m}^{2} \\
\mathrm{~m}^{2} / \mathrm{m}^{2} \\
\mathrm{~m}^{2} / \mathrm{m}^{2} \\
\mathrm{~m}^{2} / \mathrm{m}^{2} \\
\mathrm{~m}^{2} / \mathrm{m}^{2} \\
\mathrm{~m}^{2} / \mathrm{m}^{2} \\
\mathrm{~m}^{2} / \mathrm{m}^{2} \\
\mathrm{~m}^{2} / \mathrm{m}^{2}\end{array}$ \\
\hline
\end{tabular}


Table A1. Cont.

\begin{tabular}{|c|c|c|c|c|}
\hline CATEGORY & SUBCATEGORY & NAME & DESCRIPTION & UNITS \\
\hline \multirow[t]{50}{*}{ Temporal } & Phenological metrics & $\begin{array}{l}\text { SGS_doy } \\
\text { SGS_value } \\
\text { PoS_doy } \\
\text { PoS_value } \\
\text { EGS_doy } \\
\text { EGS_value } \\
\text { EoS_doy } \\
\text { EoS_value } \\
\text { greenup_doy } \\
\text { greenup_rate } \\
\text { senescence_doy } \\
\text { senescence_rate } \\
\text { amplitude } \\
\text { DoS } \\
\text { LMP } \\
\text { STI }\end{array}$ & $\begin{array}{l}\text { Start of Growing Season (DoY) } \\
\text { Start of Growing Season LAI } \\
\text { Peak of Season (DoY) } \\
\text { Peak of Season LAI } \\
\text { End of Growing Season (DoY) } \\
\text { End of Growing Season VI } \\
\text { End of Season (DoY) } \\
\text { End of Season VI } \\
\text { Greenup (DoY) } \\
\text { Greenup rate VI } \\
\text { Senescence (DoY) } \\
\text { Senescence rate LAI } \\
\text { LAI amplitude } \\
\text { Duration of season } \\
\text { Length of Maturity Plateau } \\
\text { Seasonal time integrated LAI }\end{array}$ & $\begin{array}{l}\text { DoY } \\
\mathrm{m}^{2} / \mathrm{m}^{2} \\
\text { DoY } \\
\mathrm{m}^{2} / \mathrm{m}^{2} \\
\text { DoY } \\
\mathrm{m}^{2} / \mathrm{m}^{2} \\
\text { DoY } \\
\mathrm{m}^{2} / \mathrm{m}^{2} \\
\text { DoY } \\
\mathrm{m}^{2} / \mathrm{m}^{2} \\
\text { DoY } \\
\mathrm{m}^{2} / \mathrm{m}^{2} \\
\mathrm{~m}^{2} / \mathrm{m}^{2} \\
\text { Days }^{2} \\
\text {Days }^{2} / \mathrm{m}^{2}\end{array}$ \\
\hline & \multirow{49}{*}{ Spectral data } & $\mathrm{B} 2 \mathrm{~m} 03$ & Sentinel-2 MSI B2 value at vearly month 03 & reflectance \\
\hline & & B2 m04 & Sentinel-2 MSI B2 value at yearly month 04 & reflectance \\
\hline & & B2_m05 & Sentinel-2 MSI B2 value at yearly month 05 & reflectance \\
\hline & & B2_m06 & Sentinel-2 MSI B2 value at yearly month 06 & reflectance \\
\hline & & B2_m07 & Sentinel-2 MSI B2 value at yearly month 07 & reflectance \\
\hline & & B2_m08 & Sentinel-2 MSI B2 value at yearly month 08 & reflectance \\
\hline & & B2_m09 & Sentinel-2 MSI B2 value at yearly month 09 & reflectance \\
\hline & & B2_m10 & Sentinel-2 MSI B2 value at yearly month 10 & reflectance \\
\hline & & B3_m03 & Sentinel-2 MSI B3 value at yearly month 03 & reflectance \\
\hline & & B3_m04 & Sentinel-2 MSI B3 value at yearly month 04 & reflectance \\
\hline & & B3_m05 & Sentinel-2 MSI B3 value at yearly month 05 & reflectance \\
\hline & & B3_m06 & Sentinel-2 MSI B3 value at yearly month 06 & reflectance \\
\hline & & B3_m07 & Sentinel-2 MSI B3 value at yearly month 07 & reflectance \\
\hline & & B3_m08 & Sentinel-2 MSI B3 value at yearly month 08 & reflectance \\
\hline & & B3_m09 & Sentinel-2 MSI B3 value at yearly month 09 & reflectance \\
\hline & & B3_m10 & Sentinel-2 MSI B3 value at yearly month 10 & reflectance \\
\hline & & B4_m03 & Sentinel-2 MSI B4 value at yearly month 03 & reflectance \\
\hline & & B4_m04 & Sentinel-2 MSI B4 value at yearly month 04 & reflectance \\
\hline & & B4_m05 & Sentinel-2 MSI B4 value at yearly month 05 & reflectance \\
\hline & & B4_m06 & Sentinel-2 MSI B4 value at yearly month 06 & reflectance \\
\hline & & B4_m07 & Sentinel-2 MSI B4 value at yearly month 07 & reflectance \\
\hline & & B4_m08 & Sentinel-2 MSI B4 value at yearly month 08 & reflectance \\
\hline & & B4_m09 & Sentinel-2 MSI B4 value at yearly month 09 & reflectance \\
\hline & & B4_m10 & Sentinel-2 MSI B4 value at yearly month 10 & reflectance \\
\hline & & B5_m03 & Sentinel-2 MSI B5 value at yearly month 03 & reflectance \\
\hline & & B5_m04 & Sentinel-2 MSI B5 value at yearly month 04 & reflectance \\
\hline & & B5_m05 & Sentinel-2 MSI B5 value at yearly month 05 & reflectance \\
\hline & & B5_m06 & Sentinel-2 MSI B5 value at yearly month 06 & reflectance \\
\hline & & B5_m07 & Sentinel-2 MSI B5 value at yearly month 07 & reflectance \\
\hline & & B5_m08 & Sentinel-2 MSI B5 value at yearly month 08 & reflectance \\
\hline & & B5_m09 & Sentinel-2 MSI B5 value at yearly month 09 & reflectance \\
\hline & & B5_m10 & Sentinel-2 MSI B5 value at yearly month 10 & reflectance \\
\hline & & B6_m03 & Sentinel-2 MSI B6 value at yearly month 03 & reflectance \\
\hline & & B6_m04 & Sentinel-2 MSI B6 value at yearly month 04 & reflectance \\
\hline & & B6_m05 & Sentinel-2 MSI B6 value at yearly month 05 & reflectance \\
\hline & & B6_m06 & Sentinel-2 MSI B6 value at yearly month 06 & reflectance \\
\hline & & B6_m07 & Sentinel-2 MSI B6 value at yearly month 07 & reflectance \\
\hline & & B6_m08 & Sentinel-2 MSI B6 value at yearly month 08 & reflectance \\
\hline & & B6_m09 & Sentinel-2 MSI B6 value at yearly month 09 & reflectance \\
\hline & & B6_m10 & Sentinel-2 MSI B6 value at yearly month 10 & reflectance \\
\hline & & B7_m03 & Sentinel-2 MSI B7 value at yearly month 03 & reflectance \\
\hline & & B7_m04 & Sentinel-2 MSI B7 value at yearly month 04 & reflectance \\
\hline & & B7_m05 & Sentinel-2 MSI B7 value at yearly month 05 & reflectance \\
\hline & & B7_m06 & Sentinel-2 MSI B7 value at yearly month 06 & reflectance \\
\hline & & B7_m07 & Sentinel-2 MSI B7 value at yearly month 07 & reflectance \\
\hline & & B7_m08 & Sentinel-2 MSI B7 value at yearly month 08 & reflectance \\
\hline & & B7_m09 & Sentinel-2 MSI B7 value at yearly month 09 & reflectance \\
\hline & & B7_m10 & Sentinel-2 MSI B7 value at yearly month 10 & reflectance \\
\hline & & B8_m03 & Sentinel-2 MSI B8 value at yearly month 03 & reflectance \\
\hline
\end{tabular}


Table A1. Cont.

\begin{tabular}{|c|c|c|c|c|}
\hline CATEGORY & SUBCATEGORY & NAME & DESCRIPTION & UNITS \\
\hline & \multirow{31}{*}{ Spectral data } & B8_m04 & Sentinel-2 MSI B8 value at yearly month 04 & reflectance \\
\hline & & B8_m05 & Sentinel-2 MSI B8 value at yearly month 05 & reflectance \\
\hline & & B8_m06 & Sentinel-2 MSI B8 value at yearly month 06 & reflectance \\
\hline & & B8_m07 & Sentinel-2 MSI B8 value at yearly month 07 & reflectance \\
\hline & & B8_m08 & Sentinel-2 MSI B8 value at yearly month 08 & reflectance \\
\hline & & B8_m09 & Sentinel-2 MSI B8 value at yearly month 09 & reflectance \\
\hline & & B8_m10 & Sentinel-2 MSI B8 value at yearly month 10 & reflectance \\
\hline & & B8A_m03 & Sentinel-2 MSI B8A value at yearly month 03 & reflectance \\
\hline & & B8A_m04 & Sentinel-2 MSI B8A value at yearly month 04 & reflectance \\
\hline & & B8A_m05 & Sentinel-2 MSI B8A value at yearly month 05 & reflectance \\
\hline & & B8A_m06 & Sentinel-2 MSI B8A value at yearly month 06 & reflectance \\
\hline & & B8A_m07 & Sentinel-2 MSI B8A value at yearly month 07 & reflectance \\
\hline & & B8A_m08 & Sentinel-2 MSI B8A value at yearly month 08 & reflectance \\
\hline & & B8A_m09 & Sentinel-2 MSI B8A value at yearly month 09 & reflectance \\
\hline & & B8A_m10 & Sentinel-2 MSI B8A value at yearly month 10 & reflectance \\
\hline & & B11_m03 & Sentinel-2 MSI B11 value at yearly month 03 & reflectance \\
\hline & & B11_m04 & Sentinel-2 MSI B11 value at yearly month 04 & reflectance \\
\hline & & B11_m05 & Sentinel-2 MSI B11 value at yearly month 05 & reflectance \\
\hline & & B11_m06 & Sentinel-2 MSI B11 value at yearly month 06 & reflectance \\
\hline & & B11_m07 & Sentinel-2 MSI B11 value at yearly month 07 & reflectance \\
\hline & & B11_m08 & Sentinel-2 MSI B11 value at yearly month 08 & reflectance \\
\hline & & B11_m09 & Sentinel-2 MSI B11 value at yearly month 09 & reflectance \\
\hline & & B11_m10 & Sentinel-2 MSI B11 value at yearly month 10 & reflectance \\
\hline & & B12_m03 & Sentinel-2 MSI B12 value at yearly month 03 & reflectance \\
\hline & & B12_m04 & Sentinel-2 MSI B12 value at yearly month 04 & reflectance \\
\hline & & B12_m05 & Sentinel-2 MSI B12 value at yearly month 05 & reflectance \\
\hline & & B12_m06 & Sentinel-2 MSI B12 value at yearly month 06 & reflectance \\
\hline & & B12_m07 & Sentinel-2 MSI B12 value at yearly month 07 & reflectance \\
\hline & & B12_m08 & Sentinel-2 MSI B12 value at yearly month 08 & reflectance \\
\hline & & B12_m09 & Sentinel-2 MSI B12 value at yearly month 09 & reflectance \\
\hline & & B12_m10 & Sentinel-2 MSI B12 value at yearly month 10 & reflectance \\
\hline & \multirow{35}{*}{ Biophysical index } & LAI_m01 & Sentinel-2 MSI LAI value at yearly month 01 & $\mathrm{~m}^{2} / \mathrm{m}^{2}$ \\
\hline & & LAI_m02 & Sentinel-2 MSI LAI value at yearly month 02 & $\mathrm{~m}^{2} / \mathrm{m}^{2}$ \\
\hline & & LAI_m03 & Sentinel-2 MSI LAI value at yearly month 03 & $\mathrm{~m}^{2} / \mathrm{m}^{2}$ \\
\hline & & LAI_m04 & Sentinel-2 MSI LAI value at yearly month 04 & $\mathrm{~m}^{2} / \mathrm{m}^{2}$ \\
\hline & & LAI_m05 & Sentinel-2 MSI LAI value at yearly month 05 & $\mathrm{~m}^{2} / \mathrm{m}^{2}$ \\
\hline & & LAI_m06 & Sentinel-2 MSI LAI value at yearly month 06 & $\mathrm{~m}^{2} / \mathrm{m}^{2}$ \\
\hline & & LAI_m07 & Sentinel-2 MSI LAI value at yearly month 07 & $\mathrm{~m}^{2} / \mathrm{m}^{2}$ \\
\hline & & LAI_m08 & Sentinel-2 MSI LAI value at yearly month 08 & $\mathrm{~m}^{2} / \mathrm{m}^{2}$ \\
\hline & & LAI_m09 & Sentinel-2 MSI LAI value at yearly month 09 & $\mathrm{~m}^{2} / \mathrm{m}^{2}$ \\
\hline & & LAI_m10 & Sentinel-2 MSI LAI value at yearly month 10 & $\mathrm{~m}^{2} / \mathrm{m}^{2}$ \\
\hline & & LAI_m11 & Sentinel-2 MSI LAI value at yearly month 11 & $\mathrm{~m}^{2} / \mathrm{m}^{2}$ \\
\hline & & LAI_m12 & Sentinel-2 MSI LAI value at yearly month 12 & $\mathrm{~m}^{2} / \mathrm{m}^{2}$ \\
\hline & & EVI_m03 & Sentinel-2 MSI EVI value at yearly month 03 & dimensionless \\
\hline & & EVI_m04 & Sentinel-2 MSI EVI value at yearly month 04 & dimensionless \\
\hline & & EVI_m05 & Sentinel-2 MSI EVI value at yearly month 05 & dimensionless \\
\hline & & EVI_m06 & Sentinel-2 MSI EVI value at yearly month 06 & dimensionless \\
\hline & & EVI_m07 & Sentinel-2 MSI EVI value at yearly month 07 & dimensionless \\
\hline & & EVI_m08 & Sentinel-2 MSI EVI value at yearly month 08 & dimensionless \\
\hline & & EVI_m09 & Sentinel-2 MSI EVI value at yearly month 09 & dimensionless \\
\hline & & EVI_m10 & Sentinel-2 MSI EVI value at yearly month 10 & dimensionless \\
\hline & & NDYI_m03 & Sentinel-2 MSI NDYI value at yearly month 03 & dimensionless \\
\hline & & NDYI_m04 & Sentinel-2 MSI NDYI value at yearly month 04 & dimensionless \\
\hline & & NDYI_m05 & Sentinel-2 MSI NDYI value at yearly month 05 & dimensionless \\
\hline & & NDYI_m06 & Sentinel-2 MSI NDYI value at yearly month 06 & dimensionless \\
\hline & & NDYI_m07 & Sentinel-2 MSI NDYI value at yearly month 07 & dimensionless \\
\hline & & NDYI_m08 & Sentinel-2 MSI NDYI value at yearly month 08 & dimensionless \\
\hline & & NDYI_m09 & Sentinel-2 MSI NDYI value at yearly month 09 & dimensionless \\
\hline & & NDYI_m10 & Sentinel-2 MSI NDYI value at yearly month 10 & dimensionless \\
\hline & & RI_m03 & Sentinel-2 MSI RI value at yearly month 03 & dimensionless \\
\hline & & RI_m04 & Sentinel-2 MSI RI value at yearly month 04 & dimensionless \\
\hline & & RI_m05 & Sentinel-2 MSI RI value at yearly month 05 & dimensionless \\
\hline & & RI_m06 & Sentinel-2 MSI RI value at yearly month 06 & dimensionless \\
\hline & & RI_m07 & Sentinel-2 MSI RI value at yearly month 07 & dimensionless \\
\hline & & RI_m08 & Sentinel-2 MSI RI value at yearly month 08 & dimensionless \\
\hline & & RI_m09 & Sentinel-2 MSI RI value at yearly month 09 & dimensionless \\
\hline
\end{tabular}


Table A1. Cont.

\begin{tabular}{|c|c|c|c|c|}
\hline CATEGORY & SUBCATEGORY & NAME & DESCRIPTION & UNITS \\
\hline & \multirow{9}{*}{ Biophysical index } & RI_m10 & Sentinel-2 MSI RI value at yearly month 10 & dimensionless \\
\hline & & CRII_m03 & Sentinel-2 MSI CRI1 value at yearly month 03 & dimensionless \\
\hline & & CRI1_m04 & Sentinel-2 MSI CRI1 value at yearly month 04 & dimensionless \\
\hline & & CRI1_m05 & Sentinel-2 MSI CRI1 value at yearly month 05 & dimensionless \\
\hline & & CRI1_m06 & Sentinel-2 MSI CRI1 value at yearly month 06 & dimensionless \\
\hline & & CRI1_m07 & Sentinel-2 MSI CRI1 value at yearly month 07 & dimensionless \\
\hline & & CRI1_m08 & Sentinel-2 MSI CRI1 value at yearly month 08 & dimensionless \\
\hline & & CRI1_m09 & Sentinel-2 MSI CRI1 value at yearly month 09 & dimensionless \\
\hline & & CRI1_m10 & Sentinel-2 MSI CRI1 value at yearly month 10 & dimensionless \\
\hline
\end{tabular}

Table A2. Spectral characteristics of Sentinel-2 MSI sensor.

\begin{tabular}{|c|c|c|c|c|c|c|}
\hline $\begin{array}{l}\text { Spectral } \\
\text { Band }\end{array}$ & Band Name & $\begin{array}{c}\text { S2A Central } \\
\text { Wavelength }(\mathrm{nm})\end{array}$ & $\begin{array}{l}\text { S2A Band Width } \\
(\mathrm{nm})\end{array}$ & $\begin{array}{c}\text { S2B Central } \\
\text { Wavelength }(\mathrm{nm})\end{array}$ & $\begin{array}{l}\text { S2B Band Width } \\
(\mathrm{nm})\end{array}$ & $\begin{array}{c}\text { Resolution } \\
\text { (m) }\end{array}$ \\
\hline B1 & Coastal aerosol & 443.9 & 27 & 442.3 & 45 & 60 \\
\hline B2 & Blue & 496.6 & 98 & 492.1 & 98 & 10 \\
\hline B3 & Green & 560.0 & 45 & 559.0 & 46 & 10 \\
\hline B4 & Red & 664.5 & 38 & 665.0 & 39 & 10 \\
\hline B5 & Red edge 1 & 703.9 & 19 & 703.8 & 20 & 20 \\
\hline B6 & Red edge 2 & 740.2 & 18 & 739.1 & 18 & 20 \\
\hline B7 & Red edge 3 & 782.5 & 28 & 779.7 & 28 & 20 \\
\hline B8 & Near infrared & 835.1 & 145 & 833.0 & 133 & 10 \\
\hline B8A & Near infrared narrow & 864.8 & 33 & 864.0 & 32 & 20 \\
\hline B9 & Water vapor & 945.0 & 26 & 943.2 & 27 & 60 \\
\hline B10 & SWIR Cirrus & 1373.5 & 75 & 1376.9 & 76 & 60 \\
\hline B11 & Shortwave Infrared 1 & 1613.7 & 143 & 1610.4 & 141 & 20 \\
\hline B12 & Shortwave Infrared 2 & 2202.4 & 242 & 2185.7 & 238 & 20 \\
\hline
\end{tabular}

\section{Appendix B}

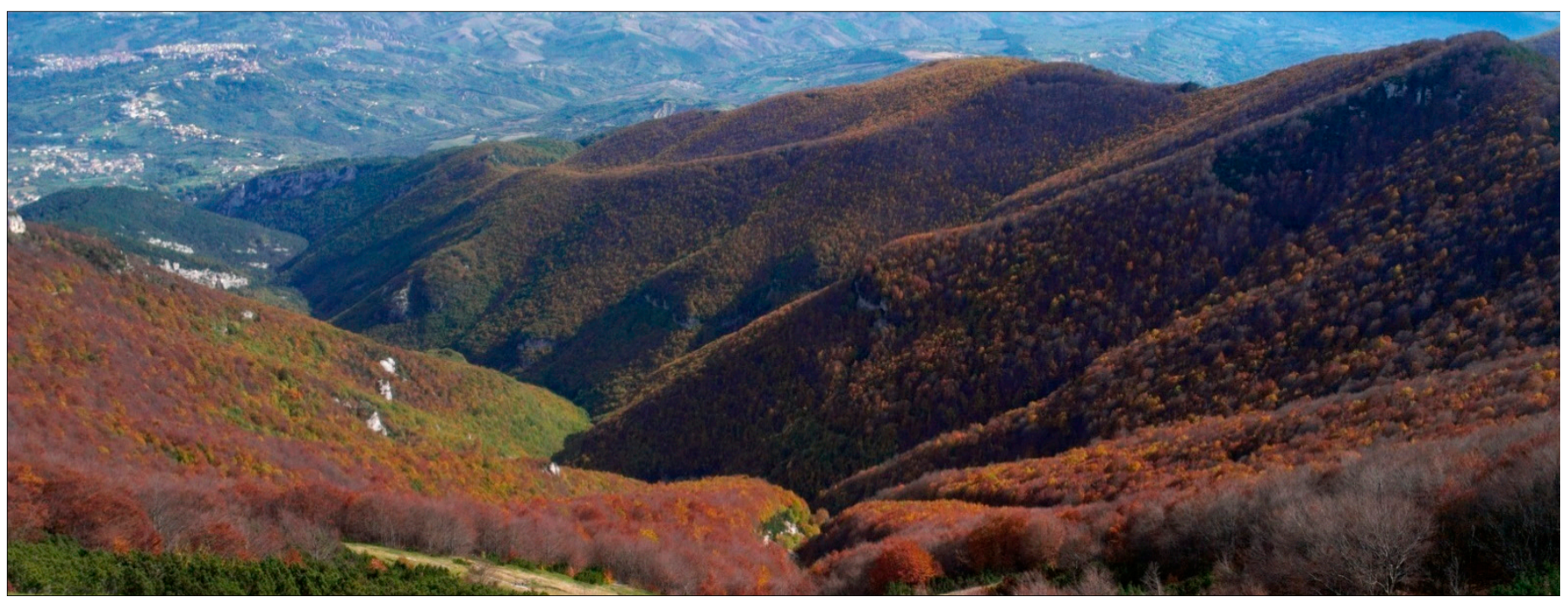

(a)

Figure A1. Cont. 


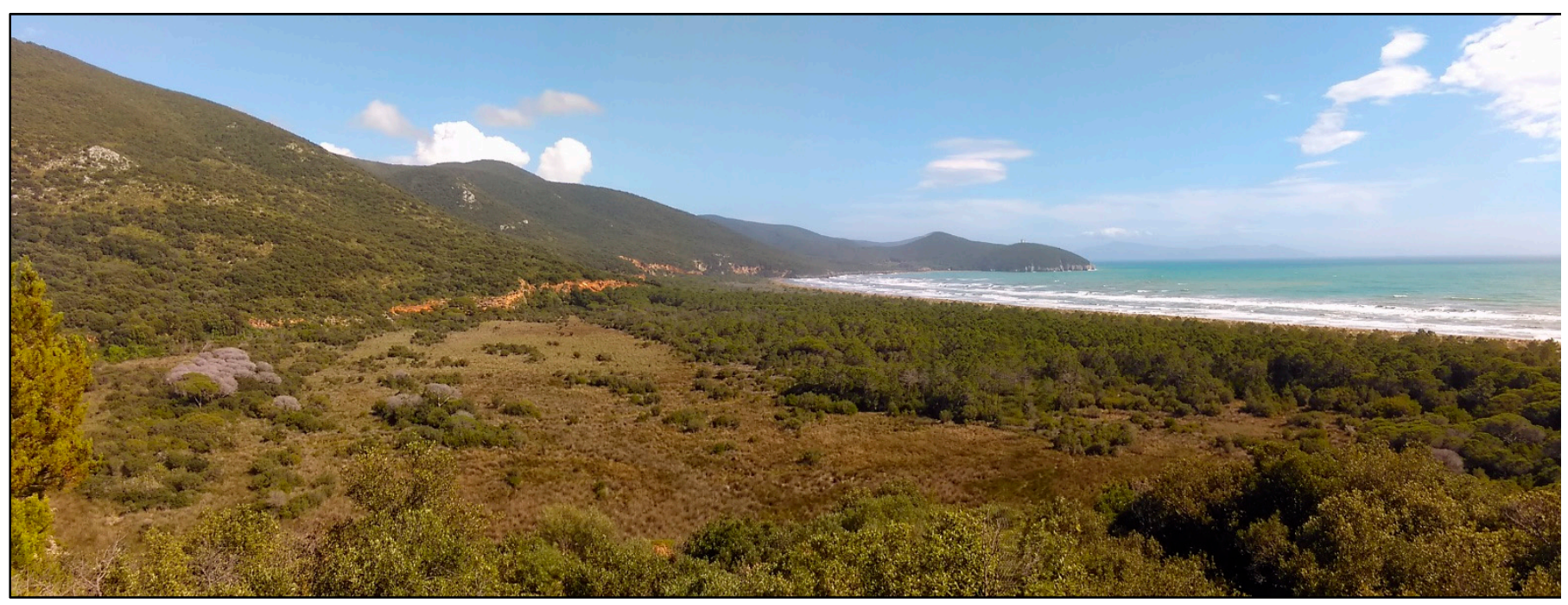

(b)

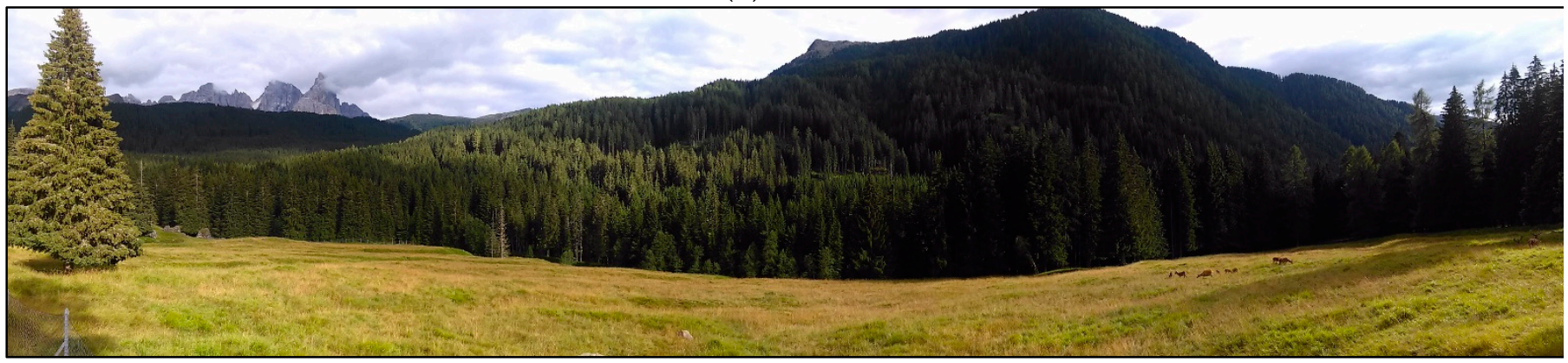

(c)

Figure A1. Pictures of woodland landscapes: (a) T1 Broadleaved Deciduous forest on Apennine chain (Photo by E. Agrillo); (b) T2 Broadleaved Evergreen forest along Tyrrhenian coast (Photo by E. Agrillo) and (c) T3 needleleaved forest habitat in the Alps range (Photo by E. Agrillo).

\section{References}

1. Steffen, W.; Richardson, K.; Rockström, J.; Cornell, S.E.; Fetzer, I.; Bennett, E.M.; Biggs, R.; Carpenter, S.R.; de Vries, W.; de Wit, C.A.; et al. Planetary boundaries: Guiding human development on a changing planet. Science 2015, 347, 1259-1855. [CrossRef] [PubMed]

2. Hooper, D.U.; Adair, E.C.; Cardinale, B.J.; Byrnes, J.E.; Hungate, B.A.; Matulich, K.L.; Gonzalez, A.; Duffy, J.E.; Gamfeldt, L.; O'Connor, M.I. A global synthesis reveals biodiversity loss as a major driver of ecosystem change. Nature 2012, 486, 105-108. [CrossRef] [PubMed]

3. Theriault, J.; Young, L.; Barrett, L.F. The sense of should: A biologically-based framework for modeling social pressure. Phys. Life Rev. 2020. [CrossRef] [PubMed]

4. Dryzek, J.S.; Norgaard, R.B.; Schlosberg, D. Climate change and society: Approaches and responses. In The Oxford Handbook of Climate Change and Society; Dryzek, J.S., Norgaard, R.B., Schlosberg, D., Eds.; Oxford University Press: Oxford, UK, 2011; pp. 3-17. [CrossRef]

5. Hampton, S.E.; Strasser, C.A.; Tewksbury, J.J.; Gram, W.K.; Budden, A.E.; Batcheller, A.L.; Duke, C.S.; Porter, J.H. Big data and the future of ecology. Front. Ecol. Environ. 2013, 11, 156-162. [CrossRef]

6. $\quad$ Runting, R.K.; Phinn, S.; Xie, Z.; Venter, O.; Watson, J.E. Opportunities for big data in conservation and sustainability. Nat. Commun. 2020, 11, 1-4. [CrossRef]

7. Hallgren, W.; Beaumont, L.; Bowness, A.; Chambers, L.; Graham, E.; Holewa, H.; Laffan, S.; Mackey, B.; Nix, H.; Price, J.; et al. The biodiversity and climate change virtual laboratory: Where ecology meets big data. Environ. Model. Softw. 2016, 76, 182-186. [CrossRef]

8. Palmer, M.A.; Bernhardt, E.S.; Chornesky, E.A.; Collins, S.L.; Dobson, A.P.; Duke, C.S.; Gold, B.D.; Jacobson, R.B.; Kingsland, S.E.; Kranz, R.H.; et al. Ecological science and sustainability for the 21st century. Front. Ecol. Environ. 2015, 3, 4-11. [CrossRef]

9. Tuomisto, H. A consistent terminology for quantifying species diversity? Yes, it does exist. Oecologia 2010, 164, 853-860. [CrossRef]

10. Convention on Biological Diversity. Available online: https://www.cbd.int/convention/text/ (accessed on 12 December 2020). 
11. Klijn, F.; Groen, C.L.G.; Witte, J.P.M. Ecoseries for potential site mapping, an example from the Netherlands. Landsc. Urban Plan. 1996, 35, 53-70. [CrossRef]

12. Klijn, F. Ecosystem Classification for Environmental Management; Springer: Berlin/Heidelberg, Germany, 2013 ; Volume 2.

13. Van der Maarel, E. Vegetation Ecology; Franklin, J., Ed.; John Wiley \& Sons: Hoboken, NJ, USA, 2012.

14. Janssen, J.A.M.; Rodwell, J.S.; García Criado, M.; Arts, G.; Bijlsma, R.J.; Schaminee, J.H.J. European Red List of Habitats: Part 2. In Terrestrial and Freshwater Habitats; Publications Office of the European Union: Luxembourg, 2016; ISBN 978-92-79-61588-7. [CrossRef]

15. Bijlsma, R.J.; Agrillo, E.; Attorre, F.; Boitani, L.; Brunner, A.; Evans, P.; Foppen, R.; Gubbay, S.; Jansenn, J.A.M.; van Klaunen, A.; et al. Defining and Applying the Concept of Favourable Reference Values for Species Habitats under the EU Birds and Habitats Directives: Examples of Setting Favourable Reference Values; Report No. 2929; Wageningen Environmental Research: Wageningen, The Netherlands, 2018.

16. Dengler, J.; Oldeland, J.; Jansen, F.; Chytry, M.; Ewald, J.; Finckh, M.; Glockler, F.; Lopez-Gonzalez, G.; Peet, R.K.; Schaminee, J.H.J. Vegetation databases for the 21st century. Biodivers. Ecol. 2012, 4, 15-24. [CrossRef]

17. Chytrý, M.; Hennekens, S.M.; Jiménez-Alfaro, B.; Knollová, I.; Dengler, J.; Jansen, F.; Landucci, F.; Schaminée, J.H.; Acìc, S.; Agrillo, E.; et al. European Vegetation Archive (EVA): An integrated database of European vegetation plots. Appl. Veg. Sci. 2016, 19, 173-180. [CrossRef]

18. Bruelheide, H.; Dengler, J.; Jiménez-Alfaro, B.; Purschke, O.; Hennekens, S.M.; Chytrý, M.; Pillar, V.D.; Jansen, F.; Kattge, J.; Sandel, B.; et al. sPlot-A new tool for global vegetation analyses. J. Veg. Sci. 2019, 30, 161-186. [CrossRef]

19. Davies, C.E.; Moss, D. EUNIS Habitats Classification. In Final Report to the European Topic Centre on Nature Conservation; European Environment Agency: Copenhagen, Denmark, 1998.

20. Davies, C.E.; Moss, D.; Hill, M.O. EUNIS Habitat Classification; European Environment Agency: Copenhagen, Denmark, 2004.

21. EUNIS European Nature Information System. Available online: https://www.eea.europa.eu/data-and-maps/data/eunishabitat-classification (accessed on 18 October 2020).

22. Chytrý, M.; Tichý, L.; Hennekens, S.M.; Knollová, I.; Janssen, J.A.; Rodwell, J.S.; Peterka, T.; Marcenò, C.; Landucci, F.; Danihelka, J.; et al. EUNIS Habitat Classification: Expert system, characteristic species combinations and distribution maps of European habitats. Appl. Veg. Sci. 2020. [CrossRef]

23. Revision of the EUNIS Habitat Classification. Available online: https://www.eea.europa.eu/themes/biodiversity/anintroduction-to-habitats / underpinning-european-policy-on-nature-conservation-1 (accessed on 15 November 2020).

24. Guo, H.; Wang, L.; Liang, D. Big Earth Data from space: A new engine for Earth science. Sci. Bull. 2016, 61, 505-513. [CrossRef]

25. Taramelli, A.; Tornato, A.; Magliozzi, M.L.; Mariani, S.; Valentini, E.; Zavagli, M.; Costantini, M.; Nieke, J.; Adams, J.; Rast, M. An Interaction Methodology to Collect and Assess User-Driven Requirements to Define Potential Opportunities of Future Hyperspectral Imaging Sentinel Mission. Remote Sens. 2020, 12, 1286. [CrossRef]

26. Marvin, D.C.; Koh, L.P.; Lynam, A.J.; Wich, S.; Davies, A.B.; Krishnamurthy, R.; Stokes, E.; Starkey, R.; Asner, G.P. Integrating technologies for scalable ecology and conservation. Glob. Ecol. Cons. 2016, 7, 262-275. [CrossRef]

27. Pettorelli, N.; Laurance, W.F.; O’Brien, T.G.; Wegmann, M.; Nagendra, H.; Turner, W. Satellite remote sensing for applied ecologists: Opportunities and challenges. J. Appl. Ecol. 2014, 51, 839-848. [CrossRef]

28. Corbane, C.; Lang, S.; Pipkins, K.; Alleaume, S.; Deshayes, M.; Millán, V.E.G.; Strasser, T.; Borre, J.V.; Toon, S.; Michael, F. Remote sensing for mapping natural habitats and their conservation status-New opportunities and challenges. Int. J. Appl. Earth Obs. 2015, 37, 7-16. [CrossRef]

29. Álvarez-Martínez, J.M.; Jiménez-Alfaro, B.; Barquín, J.; Ondiviela, B.; Recio, M.; Silió-Calzada, A.; Juanes, J.A. Modelling the area of occupancy of habitat types with remote sensing. Methods Ecol. Evol. 2018, 9, 580-593. [CrossRef]

30. Wicaksono, P.; Aryaguna, P.A.; Lazuardi, W. Benthic habitat mapping model and cross validation using machine-learning classification algorithms. Remote Sens. 2019, 11, 1279. [CrossRef]

31. Wang, R.; Gamon, J.A. Remote sensing of terrestrial plant biodiversity. Remote Sens. Environ. 2019, 231, 111218. [CrossRef]

32. Adamo, M.; Tomaselli, V.; Tarantino, C.; Vicario, S.; Veronico, G.; Lucas, R.; Blonda, P. Knowledge-Based Classification of Grassland Ecosystem Based on Multi-Temporal WorldView-2 Data and FAO-LCCS Taxonomy. Remote Sens. 2020, $12,1447$. [CrossRef]

33. Pesaresi, S.; Mancini, A.; Quattrini, G.; Casavecchia, S. Mapping Mediterranean Forest Plant Associations and Habitats with Functional Principal Component Analysis Using Landsat 8 NDVI Time Series. Remote Sens. 2020, 12, 1132. [CrossRef]

34. Valentini, E.; Taramelli, A.; Filipponi, F.; Giulio, S. An effective procedure for EUNIS and Natura 2000 habitat type mapping in estuarine ecosystems integrating ecological knowledge and remote sensing analysis. Ocean Coast. Manag. 2015, 108, 52-64. [CrossRef]

35. Valentini, E.; Taramelli, A.; Cappucci, S.; Filipponi, F.; Nguyen Xuan, A. Exploring the Dunes: The Correlations between Vegetation Cover Pattern and Morphology for Sediment Retention Assessment Using Airborne Multisensor Acquisition. Remote Sens. 2020, 12, 1229. [CrossRef]

36. Marzialetti, F.; Giulio, S.; Malavasi, M.; Sperandii, M.G.; Acosta, A.T.R.; Carranza, M.L. Capturing Coastal Dune Natural Vegetation Types Using a Phenology-Based Mapping Approach: The Potential of Sentinel-2. Remote Sens. 2019, 11, 1506. [CrossRef] 
37. Spadoni, G.L.; Cavalli, A.; Congedo, L.; Munafò, M. Analysis of Normalized Difference Vegetation Index (NDVI) multi-temporal series for the production of forest cartography. Remote Sens. Appl. Soc. Environ. 2020, 20, 100419. [CrossRef]

38. Rüetschi, M.; Schaepman, M.E.; Small, D. Using multitemporal sentinel-1 c-band backscatter to monitor phenology and classify deciduous and coniferous forests in northern switzerland. Remote Sens. 2018, 10, 55. [CrossRef]

39. Rocchini, D.; Salvatori, N.; Beierkuhnlein, C.; Chiarucci, A.; de Boissieu, F.; Foerster, M.; Garzon-Lopez, C.X.; Gillespie, T.W.; Hauffe, H.C.; He, K.S.; et al. From local spectral species to global spectral communities: A benchmark for ecosystem diversity estimate by remote sensing. Ecol. Inform. 2020, 61, 101195. [CrossRef]

40. Chytrý, M.; Schaminée, J.H.; Schwabe, A. Vegetation survey: A new focus for Applied Vegetation Science. Appl. Veg. Sci. 2011, 14. [CrossRef]

41. EU Biodiversity Strategy for 2030. Available online: https://ec.europa.eu/environment/nature/biodiversity/strategy/index_en. htm (accessed on 12 December 2020).

42. United Nations 2030 Agenda for Sustainable Development. Available online: https://sdgs.un.org/2030agenda (accessed on 23 November 2020).

43. Berry, P.; Smith, A.; Eales, R.; Papadopoulou, L.; Erhard, M.; Meiner, A.; Bastrup-Birk, A.; Ivits, E.; Royo Gelabert, E.; Dige, G.; et al. Mapping and Assessing the Condition of Europe's Ecosystems-Progress and Challenges, 3rd ed.; Publications Office of the European Union: Luxembourg, 2016; ISBN 978-92-79-55019-5. [CrossRef]

44. Copernicus Land Monitoring System. Available online: https://land.copernicus.eu (accessed on 3 October 2020).

45. Piedelobo, L.; Taramelli, A.; Schiavon, E.; Valentini, E.; Molina, J.-L.; Nguyen Xuan, A.; González-Aguilera, D. Assessment of Green Infrastructure in Riparian Zones Using Copernicus Programme. Remote Sens. 2019, 11, 2967. [CrossRef]

46. Taramelli, A.; Lissoni, M.; Piedelobo, L.; Schiavon, E.; Valentini, E.; Nguyen Xuan, A.; González-Aguilera, D. Monitoring Green Infrastructure for Natural Water Retention Using Copernicus Global Land Products. Remote Sens. 2019, 11, 1583. [CrossRef]

47. ESA-Sentinel Online. Available online: https://sentinel.esa.int/web/sentinel/home (accessed on 12 October 2020).

48. Franklin, J. Moving beyond static species distribution models in support of conservation biogeography. Divers. Distrib. 2010, 16, 321-330. [CrossRef]

49. Maggini, R.; Lehmann, A.; Zimmermann, N.E.; Guisan, A. Improving generalized regression analysis for the spatial prediction of forest communities. J. Biogeogr. 2006, 33, 1729-1749. [CrossRef]

50. Miller, J.; Franklin, J. Modeling the distribution of four vegetation alliances using generalized linear models and classification trees with spatial dependence. Ecol. Model. 2002, 157, 227-247. [CrossRef]

51. Engler, R.; Waser, L.T.; Zimmermann, N.E.; Schaub, M.; Berdos, S.; Ginzler, C.; Psomas, A. Combining ensemble modeling and remote sensing for mapping individual tree species at high spatial resolution. For. Ecol. Manag. 2013, 310, 64-73. [CrossRef]

52. Kattenborn, T.; Lopatin, J.; Förster, M.; Braun, A.C.; Fassnacht, F.E. UAV data as alternative to field sampling to map woody invasive species based on combined Sentinel-1 and Sentinel-2 data. Remote Sens. Environ. 2019, 227, 61-73. [CrossRef]

53. Vila-Viçosa, C.; Arenas-Castro, S.; Marcos, B.; Honrado, J.; García, C.; Vázquez, F.M.; Almeida, R.; Gonçalves, J. Combining Satellite Remote Sensing and Climate Data in Species Distribution Models to Improve the Conservation of Iberian White Oaks (Quercus L.). ISPRS Int. J. Geo-Inf. 2020, 9, 735. [CrossRef]

54. Gavish, Y.; O'Connell, J.; Marsh, C.J.; Tarantino, C.; Blonda, P.; Tomaselli, V.; Kunin, W.E. Comparing the performance of flat and hierarchical Habitat/Land-Cover classification models in a NATURA 2000 site. ISPRS J. Photogramm. 2018, 136, 1-12. [CrossRef]

55. Immitzer, M.; Neuwirth, M.; Böck, S.; Brenner, H.; Vuolo, F.; Atzberger, C. Optimal Input Features for Tree Species Classification in Central Europe Based on Multi-Temporal Sentinel-2 Data. Remote Sens. 2019, 11, 2599. [CrossRef]

56. Compendium of EO Contributions to the SDGs Just Released. Available online: https://eo4society.esa.int/2021/01/15 / compendium-of-eo-contributions-to-the-sdgs-just-released/ (accessed on 29 December 2020).

57. Guisan, A.; Zimmermann, N.E. Predictive habitat distribution models in ecology. Ecol. Model. 2000, 135, 147-186. [CrossRef]

58. Guisan, A.; Thuiller, W.; Zimmermann, N.E. Habitat Suitability and Distribution Models: With Applications in R; Cambridge University Press: Cambridge, UK, 2017; ISBN 987-0521765138.

59. Marchetti, M.; Soldati, M.; Vandelli, V. The great diversity of Italian landscapes and landforms: Their origin and human imprint. In Landscapes and landforms of Italy; Springer: Berlin/Heidelberg, Germany, 2017; pp. 7-20.

60. Fratianni, S.; Acquaotta, F. The climate of Italy. In Landscapes and Landforms of Italy; Springer: Berlin/Heidelberg, Germany, 2017; pp. 29-38.

61. Land Use of Italy. Available online: https://www.isprambiente.gov.it/it/pubblicazioni/rapporti/territorio.-processi-etrasformazioni-in-italia (accessed on 18 October 2020).

62. Gasparini, P.; Di Cosmo, L. National Forest Inventory Reports—Italy. In National Forest Inventories—Assessment of Wood Availability and Use, 1st ed.; Vidal, C., Alberdi, I., Hernandez, L., Redmond, J., Eds.; Springer: Berlin/Heidelberg, Germany, 2016 ; pp. 485-506. ISBN 978-3-319-44014-9.

63. Pividori, M.; Giannetti, F.; Barbati, A.; Chirici, G. European Forest Types: Tree species matrix. In European Atlas of Forest Tree Species; San-Miguel-Ayanz, J., de Rigo, D., Caudullo, G., Houston Durrant, T., Mauri, A., Eds.; Publications Office of the European Union: Luxembourg, 2016; p. e01f162.

64. Cervellini, M.; Zannini, P.; Di Musciano, M.; Fattorini, S.; Jiménez-Alfaro, B.; Rocchini, D.; Field, R.; Vetaas, O.R.; Irl, S.D.H.; Beierkuhnlein, C.; et al. A grid-based map for the Biogeographical Regions of Europe. Biodivers. Data J. 2020, 8. [CrossRef] [PubMed] 
65. Europe Biogeographical Regions. Available online: https://www.eea.europa.eu/data-and-maps/data/biogeographical-regionseurope-3 (accessed on 3 September 2020).

66. Agrillo, E.; Alessi, N.; Massimi, M.; Spada, F.; De Sanctis, M.; Francesconi, F.; Cambria, V.E.; Attorre, F. Nationwide Vegetation Plot Database-Sapienza University of Rome: State of the art, basic figures and future perspectives. Phytocoenologia 2017, 47, 221-222. [CrossRef]

67. Tree Cover Density Layer. Available online: https://land.copernicus.eu/pan-european/high-resolution-layers/forests/treecover-density (accessed on 15 October 2020).

68. Imperviousness Layer. Available online: https://land.copernicus.eu/pan-european/high-resolution-layers/imperviousness (accessed on 15 October 2020).

69. Corine Land Cover 2018 Layer. Available online: http://groupware.sinanet.isprambiente.it/uso-copertura-e-consumo-di-suolo/ library / copertura-del-suolo/corine-land-cover/corine-land-cover-2018-iv-livello (accessed on 15 October 2020).

70. Descombes, P.; Walthert, L.; Baltensweiler, A.; Meuli, R.G.; Karger, D.N.; Ginzler, C.; Ginzler, G.; Zimmermann, N.E. Spatial modelling of ecological indicator values improves predictions of plant distributions in complex landscapes. Ecography 2020, 43, 1448-1463. [CrossRef]

71. Italian Shoreline and River Network. Available online: http://www.pcn.minambiente.it/mattm/servizio-di-scaricamento-wfs / (accessed on 22 October 2020).

72. Digital Elevation Model of Italy at $20 \mathrm{~m}$ Spatial Resolution. Available online: http://www.sinanet.isprambiente.it/it/sia-ispra/ download-mais / dem20/view (accessed on 22 October 2020).

73. Braca, G.; Ducci, D. Development of a GIS based procedure (BIGBANG 1.0) for evaluating groundwater balances at National scale and comparison with groundwater resources evaluation at local scale. In Groundwater and Global Change in the Western Mediterranean Area; Springer: Berlin/Heidelberg, Germany, 2018; pp. 53-61.

74. Fioravanti, G.; Toreti, A.; Fraschetti, P.; Perconti, W.; Desiato, F. Gridded monthly temperatures over Italy. In Proceedings of the 10th EMS Annual Meeting, Zürich, Switzerland, 13-17 September 2010; p. EMS2010-306.

75. US Standard Atmosphere. 1976. Available online: https://ntrs.nasa.gov/citations/19770009539 (accessed on 24 November 2020).

76. Súri, M.; Hofierka, J. A new GIS-based solar radiation model and its application tophotovoltaic assessments. Trans. GIS 2004, 8, 175-190. [CrossRef]

77. Duveiller, G.; Filipponi, F.; Ceglar, A.; Bojanowski, J.; Alkama, R.; Stengel, M.; Cescatti, A. Widespread cloud enhancement adds further value to the world's forests. Nat. Commun. 2020. submitted.

78. Karsten, F.; Czeplak, G. Solar terrestial radiation dependent on the amount and type of clouds. Sol. Energy 1980, 24, 177-189. [CrossRef]

79. Hagolle, O.; Huc, M.; Desjardins, C.; Auer, S.; Richter, R. MAJA Algorithm Theoretical Basis Document. Available online: https: / / doi.org/10.5281/zenodo.1209633 (accessed on 7 December 2017).

80. Rouquié, B.; Hagolle, O.; Bréon, F.M.; Boucher, O.; Desjardins, C.; Rémy, S. Using Copernicus atmosphere monitoring service products to constrain the aerosol type in the atmospheric correction processor MAJA. Remote Sens. 2017, 9, 1230. [CrossRef]

81. Croft, H.; Chen, J.M. Leaf pigment content. In Reference Module in Earth Systems and Environ-Mental Sciences; Elsevier: Amsterdam, The Netherlands, 2017; pp. 1-22.

82. Huete, A.; Justice, C.; Liu, H. Development of vegetation and soil indices for MODIS-EOS. Remote Sens. Environ. 1994, 49, 224-234. [CrossRef]

83. D'Andrimont, R.; Taymans, M.; Lemoine, G.; Ceglar, A.; Yordanov, M.; van der Velde, M. Detecting flowering phenology in oil seed rape parcels with Sentinel-1 and-2 time series. Remote Sens. Environ. 2020, 239, 111660. [CrossRef]

84. Escadafal, R.; Huete, A. Improvement in remote sensing of low vegetation cover in arid regions by correcting vegetation indices for soil'noise' (Etude des proprieties spectrales des sols arides appliquee a l'amelioration des indices de vegetation obtenus par teledetection). Acad. Sci. Comptes Rendus Ser. II Mec. Phys. Chim. Sci. Terre l'Univers 1991, 312, 1385-1391.

85. Gitelson, A.A.; Zur, Y.; Chivkunova, O.B.; Merzlyak, M.N. Assessing Carotenoid Content in Plant Leaves with Reflectance Spectroscopy. Photochem. Photobiol. 2002, 75, 272-281. [CrossRef]

86. Weiss, M.; Baret, F. S2 ToolBox Level 2 Products: LAI, FAPAR, FCOVER. 2016. Available online: https://step.esa.int/docs/extra/ ATBD_S2ToolBox_L2B_V1.1.pdf (accessed on 31 March 2019).

87. Filipponi, F. Exploitation of Sentinel-2 Time Series to Map Burned Areas at the National Level: A Case Study on the 2017 Italy Wildfires. Remote. Sens. 2019, 11, 622. [CrossRef]

88. Filipponi, F.; Smiraglia, D.; Agrillo, E. Earth Observation for Phenological Metrics (EO4PM): Temporal discriminant to characterize forest ecosystems. Remote Sens.. (manuscript in preparation).

89. Gu, L.; Post, W.; Baldocchi, D.; Black, T.; Suyker, A.; Verma, S.; Vesala, T.; Wofsy, S. Characterizing the seasonal dynamics of plant community photosynthesis across a range of vegetation types. In Phenology of Ecosystem Processes; Noormets, A., Ed.; Springer: Berlin/Heidelberg, Germany, 2009; pp. 35-58. ISBN 978-1-4419-0026-5 2.

90. Pesaresi, S.; Mancini, A.; Casavecchia, S. Recognition and Characterization of Forest Plant Communities through Remote-Sensing NDVI Time Series. Diversity 2020, 12, 313. [CrossRef]

91. Zuur, A.F.; Ieno, E.N.; Elphick, C.S. A protocol for data exploration to avoid common statistical problems. Methods Ecol. Evol. 2010, 1, 3-14. [CrossRef]

92. Kursa, M.B.; Rudnicki, W.R. Feature selection with the Boruta package. J. Stat. Softw. 2010, 36, 1-13. [CrossRef] 
93. Breiman, L. Random forests. Mach. Learn. 2001, 45, 5-32. [CrossRef]

94. Wright, M.N.; Ziegler, A. Ranger: A Fast Implementation of Random Forests for High Dimensional Data in C++ and R. J. Stat. Softw. 2017, 77, 1-17. [CrossRef]

95. Attorre, F.; Cambria, V.E.; Agrillo, E.; Alessi, N.; Alfò, M.; De Sanctis, M.; Malatesta, M.; Sitzia, T.; Guarino, R.; Marcenò, C.; et al. Finite Mixture Model-based classification of a complex vegetation system. Veg. Class. Sur. 2020, 1, 77. [CrossRef]

96. Chirici, G.; Giannetti, F.; McRoberts, R.E.; Travaglini, D.; Pecchi, M.; Maselli, F.; Chiesi, M.; Corona, P. Wall-to-wall spatial prediction of growing stock volume based on Italian National Forest Inventory plots and remotely sensed data. Int. J. Appl. Earth Obs. 2020, 84, 101959. [CrossRef]

97. Genuer, R.; Poggi, J.M.; Tuleau-Malot, C.; Villa-Vialaneix, N. Random forests for big data. Big Data Res. 2017, 9, 28-46. [CrossRef]

98. Lapini, A.; Pettinato, S.; Santi, E.; Paloscia, S.; Fontanelli, G.; Garzelli, A. Comparison of Machine Learning Methods Applied to SAR Images for Forest Classification in Mediterranean Areas. Remote Sens. 2020, 12, 369. [CrossRef]

99. Probst, P.; Wright, M.N.; Boulesteix, A.L. Hyperparameters and tuning strategies for random forest. Wires Data Min. Knowl. 2019, 9. [CrossRef]

100. Bischl, B.; Lang, M.; Kotthoff, L.; Schiffner, J.; Richter, J.; Studerus, E.; Casalicchio, G.; Jones, Z.M. mlr: Machine Learning in R. J. Mach. Learn. Res. 2016, 17, 1-5. [CrossRef]

101. Stehman, S.V.; Foody, G.M. Key issues in rigorous accuracy assessment of land cover products. Remote Sens. Environ. 2019, 231, 111199. [CrossRef]

102. Pedrotti, F. Plant and Vegetation Mapping; Springer Science \& Business Media: Berlin/Heidelberg, Germany, 2012.

103. Pignatti, S.; Cavalli, R.M.; Cuomo, V.; Fusilli, L.; Pascucci, S.; Poscolieri, M.; Santini, F. Evaluating Hyperion capability for land cover mapping in a fragmented ecosystem: Pollino National Park, Italy. Remote Sens. Environ. 2009, 113, 622-634. [CrossRef]

104. Wegmann, M.; Leutner, B.; Dech, S. Remote Sensing and GIS for Ecologists: Using Open Source Software; Pelagic Publishing Ltd.: Exeter, UK, 2016.

105. Valerio, F.; Ferreira, E.; Godinho, S.; Pita, R.; Mira, A.; Fernandes, N.; Santos, S.M. Predicting Microhabitat Suitability for an Endangered Small Mammal Using Sentinel-2 Data. Remote Sens. 2020, 12, 562. [CrossRef]

106. Steinacker, C.; Beierkuhnlein, C.; Jaeschke, A. Assessing the exposure of forest habitat types to projected climate changeImplications for Bavarian protected areas. Ecol. Evol. 2019, 9, 14417-14429. [CrossRef] [PubMed]

107. Wang, Q.; Adiku, S.; Tenhunen, J.; Granier, A. On the relationship of NDVI with leaf area index in a deciduous forest site. Remote Sens. Environ. 2005, 94, 244-255. [CrossRef]

108. Zimmermann, N.E.; Edwards, T.C., Jr.; Moisen, G.G.; Frescino, T.S.; Blackard, J.A. Remote sensing-based predictors improve distribution models of rare, early successional and broadleaf tree species in Utah. J. Appl. Ecol. 2007, 44, 1057-1067. [CrossRef] [PubMed]

109. Večeřa, M.; Divíšek, J.; Lenoir, J.; Jiménez-Alfaro, B.; Biurrun, I.; Knollová, I.; Agrillo, E.; Campos, J.A.; Carni, A.; Jimènez, G.C.; et al. Alpha diversity of vascular plants in European forests. J. Biogeogr. 2019, 46, 1919-1935. [CrossRef]

110. Pesaresi, S.; Galdenzi, D.; Biondi, E.; Casavecchia, S. Bioclimate of Italy: Application of the worldwide bioclimatic classification system. J. Maps 2014, 10, 538-553. [CrossRef]

111. Saha, A.K.; Arora, M.K.; Csaplovics, E.; Gupta, R.P. Land cover classification using IRS LISS III image and DEM in a rugged terrain: A case study in Himalayas. Geocarto Int. 2005, 20, 33-40. [CrossRef]

112. Piussi, P.; Pettenella, D. Spontaneous afforestation of fallows in Italy. NEWFOR 2000, 151, 151-163.

113. Giacomini, V.; Fenaroli, L. Conosci l'Italia. Volume 2. La Flora; Touring Club Italiano: Milano, Italy, 1958.

114. Pignatti, S. I Boschi d'Italia. Sinecologia e Biodiversità; Utet: Turin, Italy, 1998.

115. Rocchini, D.; Hortal, J.; Lengyel, S.; Lobo, J.M.; Jimenez-Valverde, A.; Ricotta, C.; Bacaro, G.; Chiarucci, A. Accounting for uncertainty when mapping species distributions: The need for maps of ignorance. Progr. Phys. Geog. 2011, 35, 211-226. [CrossRef]

116. Chiarucci, A. To sample or not to sample? That is the question for the vegetation scientist. Folia Geobot. 2007, 42, 209. [CrossRef]

117. Fattorini, L.; Marcheselli, M.; Pisani, C. A three-phase sampling strategy for large-scale multi-resource forest inventories. J. Agric. Biol. Environ. Stat. 2006, 11, 296. [CrossRef]

118. Abrams, J.F.; Vashishtha, A.; Wong, S.T.; Nguyen, A.; Mohamed, A.; Wieser, S.; Kuijper, A.; Wilting, A.; Mukhopadhyay, A. Habitat-Net: Segmentation of habitat images using deep learning. Ecol. Inform. 2019, 51, 121-128. [CrossRef]

119. Chen, W.; Zheng, Q.; Xiang, H.; Chen, X.; Sakai, T. Forest Canopy Height Estimation Using Polarimetric Interferometric Synthetic Aperture Radar (PolInSAR) Technology Based on Full-Polarized ALOS/PALSAR Data. Remote Sens. 2021, 13, 174. [CrossRef] 